\title{
Capítulo
}

3

\section{Soft5G+: explorando a softwarização nas redes 5G}

\author{
Cristiano Bonato Both ${ }^{(1)}$, Kleber Vieira Cardoso ${ }^{(2)}$, Lúcio Rene Prade ${ }^{(1)}$, \\ Victor Hugo L. Lopes ${ }^{(2,3)}$, Ciro J. A. Macedo ${ }^{(2,3)}$
}

(1) PPG em Comp. Aplicada - Universidade do Vale do Rio dos Sinos

(2) Instituto de Informática - Universidade Federal de Goiás

(3) Instituto Federal de Educação Ciências e Tecnologia de Goiás

\begin{abstract}
Resumo
$O$ principal objetivo desse minicurso é apresentar o sistema $5 G$ formado por rede de acesso e núcleo, seguindo o conjunto de padrões definidos pelo 3GPP, em especial a partir do 3GPP Release 15, de março de 2018. Nesse contexto, o minicurso terá enfoque prático, mostrando as potencialidades de implementar um sistema $5 G$ a partir da softwarização. O Lançamento (Release) 15 fornecido pela $3 G P P$ introduziu uma nova arquitetura para redes celulares de próxima geração, com base em serviços. Essa Arquitetura Baseada em Serviços (Service-Based Architecture - SBA) separa estruturalmente os planos de dados e controle, com a inserção de virtualização e de fatiamento de recursos para um alto nível de desacoplamento entre as principais funções da rede de acesso e do núcleo. Assim, essa inovadora e disruptiva arquitetura oferece grande flexibilidade para o desenvolvimento e implantação de redes de próximas gerações, principalmente considerando à migração de sofisticados recursos de hardware para componentes de software executados em sistemas de nuvem. O minicurso visa apresentar projetos e implementações de componentes de software que são utilizados na rede de acesso e no núcleo. Por exemplo, os autores demonstrarão projetos de código aberto que permitem a implementação de uma rede de acesso atual, i.e., LTE/4G (projeto srsLTE), assim como sua integração com um núcleo $5 G$ (projeto free $5 G C$ ). Além disso, os autores apresentarão a utilização desses componentes de software em contêineres para explorar os serviços nativos de sistemas de nuvem no contexto 5G. Por fim, o minicurso mostrará as perspectivas e potencialidades dessa nova geração de redes que tem como principais características a flexibilidade e a programabilidade dos seus componentes. Para ilustrar essas características, os autores apresentarão abordagens para integração de redes sem fio não-3GPP para dispositivos IoT (e.g., LoRa) com uma rede $3 G P P$.
\end{abstract}




\begin{abstract}
The main goal of this short course is to present the $5 G$ system composed of the access network and the core, following the set of standards defined by the 3GPP, especially from the 3GPP Release 15, of March 2018. In this context, the short course will have a practical focus, showing the potential of implementing a $5 G$ system from software. The Release 15 provided by $3 G P P$ introduced a new architecture for next generation cellular networks, based on services. This Service-Based Architecture (SBA) separates control and data plans, and adds virtualization and resource slicing in order to achieve a high level of decoupling between the main functions from the access network and the core. Thus, this innovative and disruptive architecture offers great flexibility for the development and deployment of next-generation networks, especially considering the migration from sophisticated hardware resources to software components running on cloud systems. The short course aims to present projects and implementations of software components that are used in the access network and in the core. For example, the authors will present open source projects that allow the implementation of a current access network, that is, LTE/4G (srsLTE project), as well as its integration with a $5 G$ core (free5GC project). In addition, the authors present the use of these software components in containers to exploit the native services of cloud systems in the $5 G$ context. Finally, the short course aims to present the perspectives and potentials of this new generation of networks that have as main characteristics the flexibility and programmability of their components. To illustrate these characteristics, the authors present approaches for the integration of non-3GPP wireless networks for IoT devices (e.g., LoRa) with a 3GPP network.
\end{abstract}

\title{
3.1. Introdução
}

Antes da quinta geração, as redes móveis sem fio se focaram predominantemente no aumento da taxa de transmissão de dados e na oferta de acesso para os consumidores finais. Entretanto, mais do que apenas melhorar a largura de banda e reduzir a latência, redes 5G [1] permitem que soluções verdadeiramente disruptivas surjam em todos os tipos de indústrias [2]. Embora muitos países, como o Brasil, ainda estejam discutindo e se preparando para a implantação de redes 5G, desde 2019 vários países (e.g., China, Coreia do Sul e Estados Unidos) já estão implantando, testando e/ou efetivamente utilizando a mais recente geração de redes móveis sem fio. A expectativa é que mais de 2,4 bilhões de dispositivos utilizem redes 5G até 2025 [3]. Por enquanto, taxas próximas (e até superiores) a 1 Gbps ainda são a principal novidade, mas vários serviços, sobretudo baseados em IoT, começam a ser planejados e implantados. Carros autônomos, Indústria 4.0 e realidade virtual/aumentada/mista são algumas das apostas e costumam servir como casos de uso interessantes para as novas funcionalidades da rede. No entanto, como nas gerações anteriores, é difícil antever com acurácia quais aplicações ou serviços serão efetivamente adotados. Por enquanto, o único consenso é que redes $5 \mathrm{G}$, quando estiverem implantadas em uma escala significativa, representarão um novo passo para as comunicações sem fio e terão um impacto na sociedade tão (ou mais) profundo quanto as gerações anteriores [4].

De fato, a quinta geração representa um salto tecnológico notável em relação à quarta geração, introduzindo inovações de hardware e, sobretudo, de software significativos. É importante esclarecer que esse salto na verdade esconde os vários passos inter- 
mediários que o compõe. Na indústria de telecomunicações, inclusive por questões de publicidade, se acumula uma quantidade representativa de evoluções e novidades tecnológicas antes de definir uma geração, o que não foi diferente com redes 5G. Para ilustrar, vamos tomar como o exemplo os Lançamentos (Releases) da 3GPP (3rd Generation Partnership Project) que é uma das principais organizações de padronização de redes móveis sem fio da atualidade. Redes 4G/LTE (Long-Term Evolution) foram introduzidas em 2008 no Lançamento 8 [5] e, desde então, passaram a receber várias atualizações (representadas por novos Lançamentos) até que redes $5 \mathrm{G}$ fossem introduzidas oficialmente no Lançamento 15 [6] em 2018. Por outro lado, há fatores técnicos que também apoiam a definição de cada geração. Em redes $5 \mathrm{G}$, isso aparece no uso do espectro que, além de ampliar a utilização das bandas tradicionalmente alocadas na ordem de centenas de $\mathrm{MHz}$ até algumas unidades de $\mathrm{GHz}$, introduz ainda a utilização de bandas de dezenas de $\mathrm{GHz}$. Além disso, redes $5 \mathrm{G}$ consolidam um intenso processo de softwarização que se destaca pela adoção de sistemas de nuvem e tecnologias como virtualização [7], redes definidas por software [8], fatiamento de rede (Network Slicing) [9] e arquitetura de software baseada em serviços [10] (e microsserviços).

Além dos aspectos tecnológicos, redes 5G também introduzem mudanças no modelo de negócios das empresas. Tradicionalmente, operadores de sistemas de comunicação móvel sem fio se focavam em usuários finais como principais fontes de receita. Em redes 5G, a intenção é ampliar (ou até migrar) o foco para ter indústrias como principais clientes [11, 12]. Para dar suporte a essa ampliação do modelo de negócio das empresas de telecomunicações, três requisitos (ou cenários) principais foram definidos: Banda larga móvel aprimorada (eMBB - Enhanced Mobile Broadband), Comunicações de baixa latência ultra confiáveis (URLLC - Ultra-Reliable Low-Latency Communication) e Comunicações massivas de tipo de máquina (mMTC - Massive Machine Type Communications). Esses cenários podem ser ilustrados pela Figura 3.1(a) que foi introduzida pela ITU (International Telecommunication Union) [13], em 2015, como parte da visão do que seriam redes 5G. Essa ilustração, assim como a Figura 3.1(b), que apresenta as capacidades principais de cada cenário, são amplamente utilizadas para tentar resumir algumas propriedades relevantes de redes $5 \mathrm{G}$.

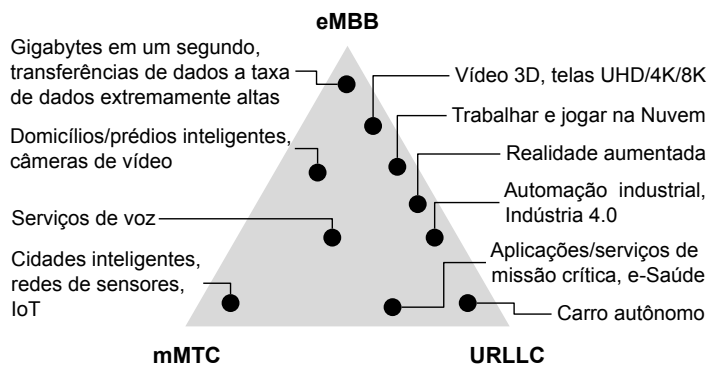

(a) Cenários 5G

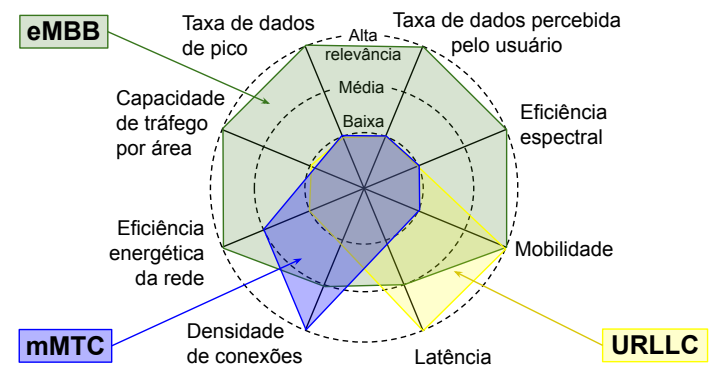

(b) Capacidades dos cenários

Figura 3.1. Cenários (ou requisitos) definidos para as redes $5 \mathrm{G}$ (à esquerda), assim como as capacidades a serem ofertadas nesses cenários (à direita).

Para atender os requisitos dos diferentes cenários, os conceitos de softwarização de rede passaram a ser adotados, tanto pela academia quanto pela indústria, para tornar 
viável o desenvolvimento de redes (ou sistemas) 5G nos últimos anos e também sua evolução [9]. O principal motivo para a introdução intensiva de software em sistemas 5G é ampliar a flexibilidade à arquitetura de rede móvel, suportando diferentes requisitos em desafiadores cenários que estão surgindo na sociedade digitalizada. Além disso, a softwarização de rede permite usufruir da computação em nuvem tradicional, assim como de suas variantes de menor escala, i.e., fog e edge. Nesse contexto, as funções de rede de acesso por rádio e núcleo passam a ser implantadas utilizando as vantagens da computação em nuvem, como armazenamento farto, processamento em larga escala, elasticidade, etc. Além de habilitar novos serviços, no longo prazo, a softwarização reduz os custos de implantação e de operação de sistemas 5G.

Dado o enfoque do minicurso na quinta geração de redes móveis celulares e sua evolução, definimos uma abordagem para descrever as informações e estruturar o texto conforme descrito a seguir. Inicialmente, o interesse está nas redes móveis para transporte de dados, embora a primeira e segunda geração dessas redes tivessem como fundamento a transmissão de voz. Adicionalmente, assumimos que uma rede móvel celular está organizada em rede de acesso por rádio e núcleo, embora essa divisão não seja tão bem definida até a terceira geração. Por fim, abordamos as redes móveis celulares sob a perspectiva de dispositivos de hardware padronizados que são controlados por componentes de software. Em geral, tanto o hardware quanto o software seguem especificações abertas que garantem sua interoperabilidade. Vale destacar que esse não é o cenário observado em redes anteriores à quarta geração, mas tende a ser a abordagem a ser seguida, a partir da quinta geração. Além disso, a quinta geração inaugura a unificação de padrões, a qual teve início com a consolidação da LTE, mas não era uma realidade no início da quarta geração, disputada também pela tecnologia WiMAX (Worldwide Interoperability for Microwave Access). Baseado na evolução das redes móveis, o minicurso também tem como objetivo apresentar as potencialidades de implementar um sistema 5G a partir da softwarização, seguindo os últimos Lançamentos da 3GPP. Adicionalmente, o minicurso introduz os principais projetos e implementações abertas de componentes de software que estão sendo utilizados em rede de acesso e núcleo, explorando os serviços nativos em nuvem para o contexto 5G. Por fim, discutimos as perspectivas dessa nova geração de redes que tem como principais características a flexibilidade e programabilidade dos seus componentes.

\subsection{Redes móveis celulares até a quarta geração}

Os primeiros sistemas de telefonia móvel empregavam um transceptor de alta potência, evoluindo para um esquema de organização com múltiplos transceptores (de menor potência) que permitiu aumentar a capacidade em termos de cobertura e reaproveitamento de recursos. Basicamente, essa é a essência das redes celulares, isto é, a sua estruturação em um conjunto de células, cada uma atendendo a uma pequena área geográfica com o uso de uma torre própria composta de antenas com transmissores de baixa potência. Para cada célula é alocada uma banda de frequências e a torre funciona como estação rádio base (transmissor, receptor e uma unidade de controle). Além de favorecer a forma de operação do sistema como um todo, auxiliando nos problemas relacionados aos efeitos de propagação dos sinais, outro benefício dessa forma de organização celular é o reuso de frequências. A coordenação entre o conjunto de células permite o reuso de uma 
mesma frequência em células próximas não adjacentes, realizando o controle da potência de transmissão e a alocação de canais [14].

\subsubsection{Operação dos sistemas celulares}

Mesmo observando que os sistemas celulares evoluíram consideravelmente desde a sua proposição, a essência do seu modo de operação não sofreu grandes modificações. A estação rádio base transceptora (BTS - Base Transceiver Station, ou simplesmente BS) contida em cada célula é composta de uma ou mais antenas, um controlador e um conjunto de transceptores para a comunicação através dos canais atribuídos à célula. Nesse contexto, o controlador é responsável por todo o processo de comunicação entre os diversos dispositivos de usuário (UE - User Equipment) ativos dentro da célula e o restante da rede. A BS opera de forma automatizada, sem necessidade de ações por parte do usuário e disponibiliza dois tipos de canais, i.e., controle e tráfego. Os canais de controle sendo utilizados para trocar informações de configuração, tais como aquelas necessárias à inicialização e manutenção de chamadas para a associação dos UEs às BSs próximas. Os canais de tráfego são utilizados para transmitir efetivamente os dados e voz dos usuários.

Originalmente, cada BS possuía conexão com o MTSO (Mobile Telecommunications Switch Office), que por sua vez, conectava-se à rede telefônica pública comutada (PSTN - Public Switched Telephone Network). Um único MTSO servia a várias BSs realizando tarefas de encaminhamento de chamadas à usuários fixos e móveis, monitoramento de controle e tarifação, manutenção de chamadas em andamento, além de paging (o procedimento utilizado para a localização da célula em que um assinante se encontra, antes de uma solicitação de início de chamada ser encaminhada) e handoff (o processo de transferência de uma chamada em andamento, ou uma sessão de dados, de uma célula à outra). Cabia às BSs o envio periódico de sinais de sincronização, permitindo aos UEs escanearem, selecionarem e monitorarem os sinais dos canais de controle disponíveis. Esses sinais periódicos auxiliavam no processo de associação dos UEs à BS mais adequada. Sempre que uma associação ocorria, um registro era realizado no MTSO, o qual controlava a célula e permitia identificar a localização de cada UE.

Na subseção a seguir, mostramos como as redes celulares evoluíram desde a primeira geração. Naturalmente, houve várias alterações e a introdução de diversas tecnologias. No entanto, a maior parte dos conceitos introduzidos no início das redes celulares ainda persiste, tais como célula, reuso de frequências, paging, handoff, dentre outros.

\subsubsection{A evolução das redes móveis}

Os sistemas de redes móveis têm evoluído de forma significativa desde que foram introduzidos, em meados dos anos 1980. Conforme descrito anteriormente, as evoluções são agrupadas sob o conceito de gerações, marcadas por um conjunto relevante novas tecnologias que alteram a oferta de serviços pela rede móvel. Apesar da quinta geração já estar entrando em operação comercial, vamos apresentar brevemente algumas características que marcaram cada uma das gerações anteriores, conforme sumarizado na Tabela 3.1 .

E interessante observar que, ainda hoje, apenas a primeira geração das redes móveis não tem nenhuma operação comercial. Ou seja, todas as demais gerações ainda possuem equipamentos em operação, pelo menos como parte de redes mais modernas. 
Tabela 3.1. Evolução das gerações: algumas características importantes [14, 15, 16].

\begin{tabular}{|c|c|c|c|c|}
\hline Implementação & $\approx 1984$ & $\mathbf{2 G}$ & $\mathbf{3 G}$ & $\mathbf{4 G}$ \\
\hline Serviços & Voz analógica & $\begin{array}{c}\text { Voz digital } \\
\text { SMS }\end{array}$ & $\begin{array}{c}\text { Pacotes de dados } \\
\text { de alta capacidade }\end{array}$ & Comunicação IP \\
\hline Taxa de dados & $1.9 \mathrm{kbps}$ & $14.4 \mathrm{kbps}$ & $384 \mathrm{kbps}$ & 200 Mbps \\
\hline Multiplexação & FDMA & TDMA, CDMA & TDMA, CDMA & OFDMA, SC-FDMA \\
\hline Rede de acesso & AMPS & $\begin{array}{c}\text { GSM, PDC, IS-95, } \\
\text { IS-136, EDGE, GPRS }\end{array}$ & $\begin{array}{c}\text { CDMA 2000, UMTS, } \\
\text { TD-SCDMA,WCDMA }\end{array}$ & LTE, WiMAX \\
\hline Núcleo da rede & PSTN & PSTN - SS & PSTN - SS, rede de pacotes & EPC \\
\hline 3GPP & - & - & Lançamento 1999 & Lançamento 8 \\
\hline
\end{tabular}

Analisando as evoluções das gerações, podemos compreender o aprimoramento das características arquiteturais (rede de acesso e núcleo) e o crescente emprego de soluções de software nessas novas gerações. Além disso, é importante contextualizar a origem do sistema analógico baseado em circuitos $(1 \mathrm{G})$, fortemente acoplado ao sistema telefônico cabeado, tornando-se parcialmente orientado a pacotes $(2 \mathrm{G}$ e $3 \mathrm{G})$ e, finalmente, oferecendo um suporte completo à comunicação de pacotes IP (4G) [16]. Cada uma dessas gerações é descrita brevemente a seguir com o objetivo de auxiliar na compreensão do atual estágio que estamos vivendo, em especial, as novidades introduzidas efetivamente na quinta geração.

\section{Primeira Geração - 1G}

A primeira geração $(1 \mathrm{G})$ dos sistemas de redes móveis sem fio foi criada para oferecer serviço de comunicação de voz analógica de forma a estender a rede telefônica comutada (PSTN). Nesse contexto, o AMPS (Advanced Mobile Phone Service) foi o padrão de rede de acesso $1 \mathrm{G}$ mais amplamente implementado. Apesar de não haver consenso sobre uma clara distinção entre rede de acesso e núcleo nesta arquitetura, observa-se que o MTSO pode ser considerado como núcleo, pois realiza tarefas de controle de handover, registro e autenticação de UEs, roteamento e gestão de ligações telefônicas (paging, handoff, etc.). Além disso, o MTSO interliga a PSTN às múltiplas BTSs [17], que por sua vez realizam as conexões com UEs, através de canais analógicos em modulação por frequência (FM - Frequency Modulation) e acesso múltiplo aos poucos canais disponíveis via FDMA (Frequency Division Multiple Access), em um espectro licenciado. Apesar de apresentar várias limitações (como canais de baixa capacidade e taxa de dados, limitação do uso da banda pela adoção de modulação única para voz e dados de controle, além de falta de criptografia), um importante caminho foi aberto levando em direção às próximas gerações.

\section{Segunda Geração - 2G}

O sistema $2 \mathrm{G}$ foi introduzido no início dos anos 90 e apresentou suporte a modulações digitais, apesar de ainda continuar baseado na transmissão de dados com comutação por circuitos, em sua primeira versão. Essa técnica de modulação proporcionou a oferta de serviços de voz digital e pacotes de dados básicos, com serviço de mensagens curtas 
de texto (SMS - Short Message Service). O emprego de novas modulações, com canais ofertando uma maior capacidade, bem como a inclusão de novas técnicas de detecção e correção de erros e algoritmo de compressão e descompressão [18], melhorou a qualidade de serviço (QoS - Quality of Service) para os usuários finais. Além disso, maiores taxas de transmissão de dados (Tabela 3.1) e eficiência espectral foram alcançadas com a introdução de métodos de acesso dinâmico, como o acesso múltiplo por divisão de tempo (TDMA - Time Division Multiple Access) e por divisão de código (CDMA - Code Division Multiple Access) [14].

Toda a família do sistema $2 \mathrm{G}$ ainda está operacional hoje em dia, sendo que importantes evoluções foram implementadas para dar suporte ao incremento da demanda por serviços de dados. O Sistema Global de Comunicações Móveis (GSM - Global System for Mobile Communications) é a primeira versão implementada, seguido pela 2,5G, o qual utiliza o padrão GPRS (General Packet Radio Service), introduzindo o suporte à comutação por pacotes. Essa evolução foi finalizada com a chamada geração 2,75G, através da tecnologia EDGE (Enhanced Date Rates For GSM Evolution), que apresentou um padrão de melhoria nas taxas de dados para o GSM [19, 18]. Já na segunda geração, podemos observar a dificuldade em definir as fronteiras e a qual geração atribuir cada inovação.

Sob o ponto de vista arquitetural, o sistema $2 \mathrm{G}$, ilustrado na Figura 3.2, é composto pelo sistema de estações rádio base (BSS -Base Station System), com o papel de RAN (Radio Access Network) para os usuários móveis GSM (MS - Mobile Station) e o sistema de comutação (SS - Switching System) como o núcleo da rede [20, 21]. O BSS é composto de diversas BTSs interligadas e coordenadas por controladores de estações rádio base (BSC - Base Station Controller). O SS encontra-se na camada da rede, com a responsabilidade de gerenciar o BSS, provendo a comutação de chamadas (PSTN) através do centro de comutação móvel (MSC - Mobile Switching Center), e a comutação dos pacotes para a rede de dados por intermédio do nó de suporte ao tráfego de dados GPRS (SGSN - Serving GPRS Support Node). Além disso, o SS realiza serviços de registro e autenticação de usuários locais e visitantes (HLR Home Location Register, VLR - Visitor Location Register e AUC - Authentication Center) e o registro de identificação de equipamentos (EIR - Equipment Identity Register). Toda a comunicação externa (PSTN e ISDN - Integrated Services Digital Network) é realizada por intermédio do gateway do centro de comutação móvel (GMSC - Gateway Mobile Switching Center) [22].

\section{Terceira Geração - 3G}

Os benefícios introduzidos pela segunda geração ampliaram a implantação global e o interesse do público geral em redes móveis. Desta forma, novas demandas foram geradas, tanto para a academia, quanto para a indústria, e tais esforços culminaram na terceira geração (3G). Essa geração foi introduzida no início do novo milênio para ofertar taxas de dados ainda maiores para a época, com melhor QoS e cobertura do sinal. Além disso, $3 \mathrm{G}$ consolidou o suporte à comunicação sem fio com altas taxas de transmissão para serviços multimídia, i.e., dados, voz e vídeo. Entre muitos padrões 3G, o CDMA de banda larga (WCDMA - Wideband CDMA) foi amplamente adotado [23]. Os requisitos definidos para essa geração foram descritos em uma iniciativa da ITU no ano 2000 (IMT- 


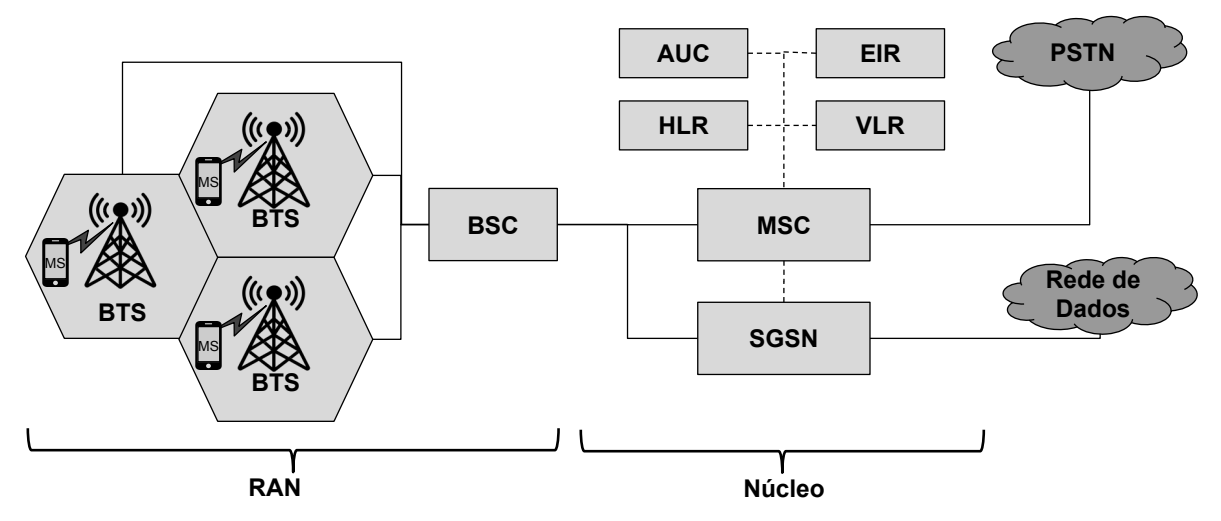

Figura 3.2. Visão geral da arquitetura GSM/GPRS (adaptado de [20]).

2000 - International Mobile Telecommunications), na qual se destacam:

- Qualidade de voz comparável à rede telefônica pública comutada;

- Taxa de transmissão de dados de 144 kbps para usuários em altas velocidades em áreas amplas (veículos automotores);

- 384 kbps de taxa de transmissão de dados para pedestres com baixa mobilidade em áreas pequenas;

- Suporte para serviços comutados por pacotes e por circuitos;

- Interface adaptativa que permite assimetria entre tráfego enviado e recebido para a rede de dados (Internet);

- Melhorias na eficiência espectral;

- Suporte para uma ampla variedade de dispositivos móveis;

- Flexibilidade para a inclusão de novos serviços e tecnologias.

Surgida com o propósito de especificar completamente esta geração, a 3GPP consolida-se como importante organização de padronização, em que as especificações são organizadas em documentos chamados lançamentos (releases), frutos de esforços dos seus 3 diferentes grupos de especificações técnicas: 1) RAN, 2) Serviços e Aspectos dos Sistemas e o Núcleo da Rede e 3) Terminais de Usuários. A terceira geração foi inicialmente especificada no lançamento 1.999, no qual as alterações arquiteturais necessárias ao atendimento dos requisitos foram apresentadas [24]. Posteriormente, outras importantes alterações foram apresentadas nos Lançamentos 5 e 6 (3,5G). O subsistema da rede de rádio (RNS - Radio Network Subsystem) que forma a RAN terrestre UMTS (ULTRAN) é composta de estações rádio base do tipo Nó B (NodeB), as quais substituem as BTSs da geração anterior, controladas por RNCs (Radio Network Controller). Mesmo não havendo uma alteração arquitetural tão significativa em relação à $2 \mathrm{G}$, um importante requisito básico do Lançamento 99 é o fornecimento de acesso por parte da ULTRAN à infraestrutura 
GSM/GPRS existente sem grandes impactos ao núcleo da rede [25], mantendo a coexistência dos comutadores por circuitos e por pacotes.

\section{Quarta Geração - 4G}

A melhoria dos sistemas de comunicação sem fio em conjunto com uma significativa evolução e popularização dos dispositivos móveis de usuários, especialmente smartphones e tablets, impulsionaram a indústria de telecomunicações no final da primeira década deste século. Esses dispositivos passaram a contar com bons recursos computacionais e contribuíram para um ininterrupto crescimento da demanda por serviços de banda larga móvel, com altas taxas de dados e QoS. Essa grande demanda abriu o caminho para uma nova geração de padrões e sistemas. A demanda fez com que a 3GPP iniciasse dois projetos em paralelos, ( $i$ ) a Evolução de Longo Prazo (LTE), ou E-UTRAN (Evolved Universal Terrestrial Access Network) [26], com foco na definição de uma nova RAN e (ii) a Evolução da Arquitetura do Sistema (SAE - System Architecture Evolution), para a proposição de um novo núcleo da rede. Baseado nesses projetos, surgiu a arquitetura EPS (Evolved Packet System), com suas especificações iniciais publicadas pela 3GPP no Lançamento 8 em 2009 [5]. Esse lançamento teve como objetivo atender às diretivas apontadas pela ITU [27], tais como:

- Ser integralmente baseado em comutação por pacotes IP;

- Suportar taxas de dados de pico de até aproximadamente 100 Mbps, para acesso móvel de alta mobilidade, e 1 Gbps, para acesso móvel de baixa mobilidade;

- Incrementar a capacidade de atendimento de usuários por célula com uso de recursos de rede compartilhados;

- Suportar a conexão simultânea a duas ou mais células durante uma conexão para oferecer transição suave (smooth handover) em redes heterogêneas;

- Suportar aplicações multimídia de próxima geração de alta qualidade.

Dois padrões emergiram dos esforços globais para padronização da $4 \mathrm{G}$, sendo o LTE desenvolvido pela 3GPP e o IEEE 802.16 desenvolvido por um grupo de trabalho do IEEE (Institute of Electrical and Electronics Engineers), também chamado de WiMAX, conforme sugerido pelo consórcio de seus fabricantes. O grupo de trabalho do IEEE 802.16 foi motivado pelo enorme sucesso do IEEE 802.11 (ou WiFi), para a comunicação sem fio em redes locais. Entretanto, WiMAX teve como objetivo a operação em comunicações sem fio fixas de alta velocidade (de dados), de forma a satisfazer as necessidades da 4G. Os dois padrões se mostraram equivalentes em termos de desempenho e tecnologia [14], baseados em acesso múltiplo via multiplexação ortogonal por divisão de frequência (OFDMA - Orthogonal Frequency Division Multiplexing / Multiple Access). Desta forma, o WiMAX assumiu um importante papel como tecnologia de acesso sem fio de banda larga fixa, enquanto o LTE se tornou o padrão universal para a interface aérea da 4G. A escala alcançada pelo LTE e a sua capacidade de oferecer um serviço semelhante 
ao WiMAX em redes sem fio de banda larga fixa são alguns fatores que tornaram o padrão da 3 GPP dominante na $4 \mathrm{G}$.

O padrão LTE define uma rede de acesso composta por estações rádio base do tipo NodeB evoluída (eNB - evolved NodeB), as quais são interligadas entre si e com o núcleo EPC. Uma rede LTE implementa modulações de alta ordem (64 QAM ou superior) com alta largura de banda (superior a $10 \mathrm{MHz}$ ), com multiplexação espacial em downlink (4x4 ou superior), oferecendo uma grande melhoria na taxa de transmissão de dados e, consequentemente, no desempenho da recepção (conforme resumido na Tabela 3.1). Além das grandes mudanças na interface aérea, outro aspecto disruptivo introduzido no sistema 4G é a arquitetura de rede plana de rádio e núcleo. Essa arquitetura permite inserir menos dispositivos intermediários e uma estrutura menos hierárquica para a rede, sem a existência de controladores centralizados. Desta forma, reduz a latência nos processos de conexões dos UEs e no tempo necessário para o handover, além de gerar outras facilidades, como simplificação da camada de enlace. Essa característica de uma arquitetura plana permitiu a expansão de serviços de telefonia móvel para as redes de pacotes IP [28], também abrindo caminho para a introdução da softwarização nesses sistemas. A Figura 3.3 ilustra uma visão geral da evolução arquitetural desde a $2 \mathrm{G}$, na qual podemos observar a evolução na rede de acesso, o método de acesso dinâmico empregado, bem como a dependência do controlador centralizado e o tipo de comutação no núcleo da rede.

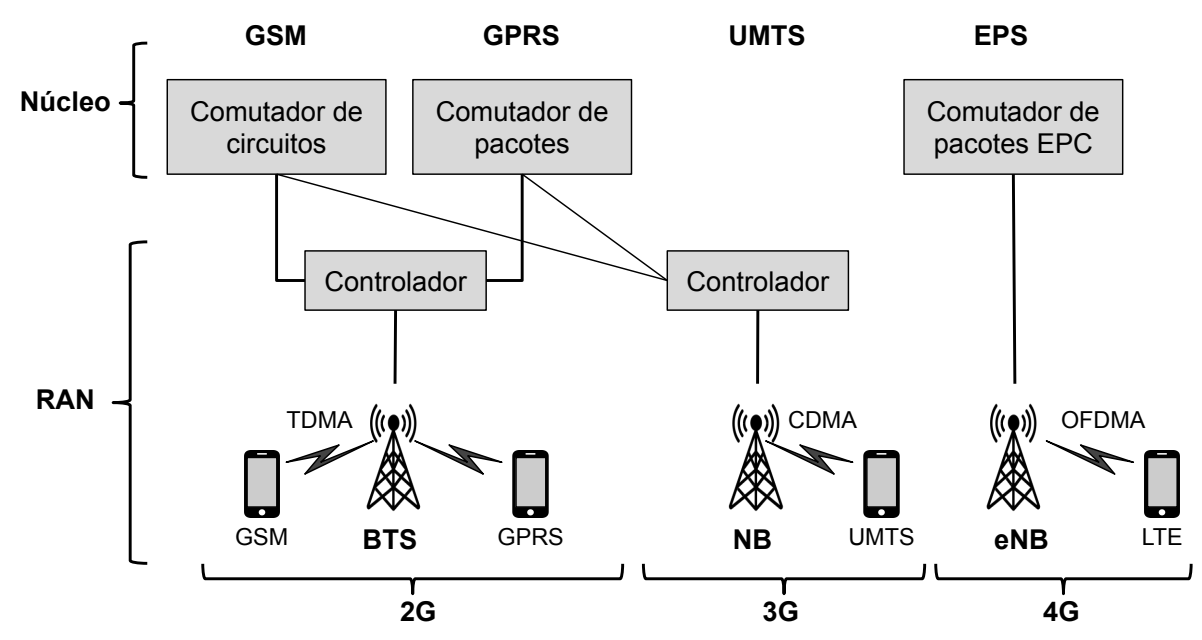

Figura 3.3. Visão geral da evolução arquitetural das redes móveis (adaptado de [26]).

\section{LTE-Advanced}

Devido à continua demanda por melhorias nas redes móveis, a 3GPP apresentou no Lançamento 10 avanços na interface aérea e na arquitetura de núcleo, dando origem ao LTE-Advanced (ou simplesmente LTE-A) [29]. A Figura 3.4 apresenta os elementos da configuração do LTE-A e os planos de dados e controle. Além disso, nessa arquitetura, cada $e N o d e B$ implementa um controlador próprio (BBU - Baseband Unit), mantendo o EPC com a responsabilidade de interconectar todos os elementos arquiteturais. A funcionalidade dos componentes principais do EPC são descritas a seguir.

- HSS - Home Subscriber Server: mantém um banco de dados que contém informa- 
ções de usuários e UEs, dando suporte às funções de gerenciamento de mobilidade, configuração de sessões e chamadas, autenticação e autorização de acesso.

- PCRF - Policy and Charging Rules Function: provê o suporte para a detecção de fluxo de dados para aplicação de políticas e cobranças de serviços de dados.

- MME - Mobility Management Entity: entidade de gerenciamento de mobilidade que lida com o controle de sinalização para rastreamento, controle de segurança e paging de UEs em modo ativo.

- S-GW - Serving Gateway: lida com os pacotes de dados IP enviados e recebidos pelos UEs, sendo o ponto de interconexão entre RAN e EPC, para o fluxo de dados entre as eNodeBs.

- P-GW - Packet Data Network (PDN) Gateway: é o ponto de interconexão entre EPC e as redes IP externas, roteando os pacotes, além de lidar com a alocação de endereço IP e controle de políticas de tarifação.

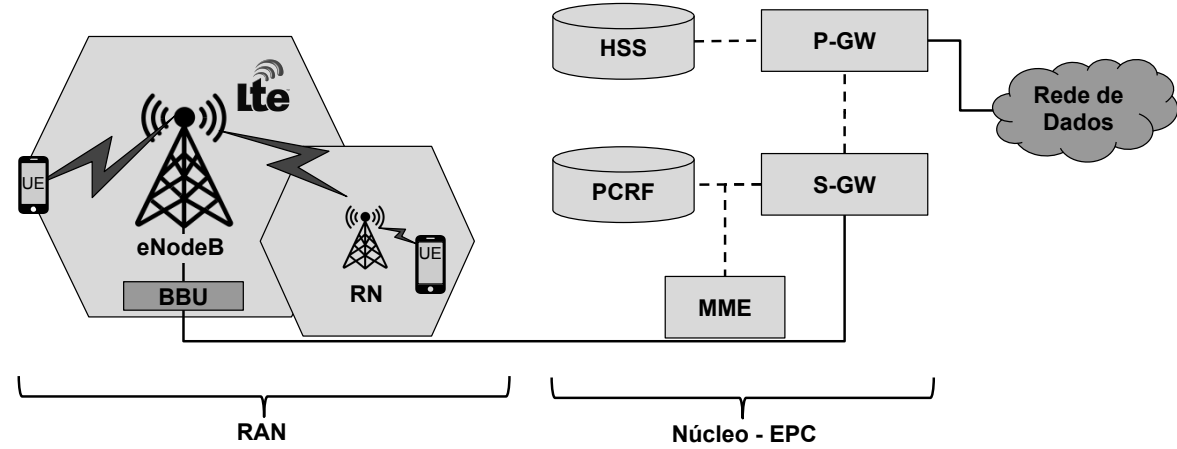

Figura 3.4. Elementos da arquitetura LTE-Advanced (adaptado de [14]).

O LTE-A continuou sendo aprimorado em outros lançamentos da 3GPP, cujo objetivo foi fornecer taxas de bits mais altas de maneira econômica e, ao mesmo tempo, cumprir completamente os requisitos estabelecidos pela ITU para a 4G. Entre esses requisitos está uma maior taxa de dados de pico (tanto para uplink quanto para downlink), maior eficiência espectral, maior número de UEs ativos simultaneamente e melhor desempenho nas bordas da célula. Outros avanços do LTE-A incluem o emprego de agregação de portadoras e melhorias nas técnicas de múltiplas antenas (MIMO - Multiple-Input and Multiple-Output) para suportar nós secundários retransmissores (RN - Relay Nodes).

A inclusão dos RNs visou resolver a queda da qualidade do sinal e taxas de transmissão nas bordas das células, causadas pela redução do nível do sinal e incremento de interferências. De uma forma simplificada, um RN é uma célula de menor raio de operação, distribuída nas regiões de fronteira das células principais. É importante destacar que não se trata de um simples repetidor de sinal, pois tem a capacidade de demodular e decodificar os sinais da $e N o d e B$ (neste contexto, chamada de donor eNodeB), aplicando correções de erros, quando necessário, operando tanto em donwlink quanto em uplink. 
Outras importantes evoluções foram incluídas ao LTE-Advanced, onde destacamos as alterações arquiteturais promovidas pelo Lançamento 14 da 3GPP [30]. Nessa atualização, foi introduzida a EPC-CUPS (Control and User Plane Separation), ilustrada na Figura 3.5 (parte direita da imagem) em comparação com a arquitetura EPC tradicional (parte esquerda da imagem). No entanto, CUPS também pode ser considerada uma funcionalidade da arquitetura 5G Não-Autônoma (NSA - Non-Stand Alone), a qual será apresentada na próxima seção. Portanto, descreveremos CUPS e outras evoluções posteriormente, no contexto da arquitetura 5G NSA. Vale relembrar que as gerações das redes móveis celulares possuem diferenças claras, mas suas fronteiras não são bem definidas quando observamos as evoluções introduzidas em cada lançamento 3GPP, especialmente nos que marcam uma transição (como o Lançamento 14).

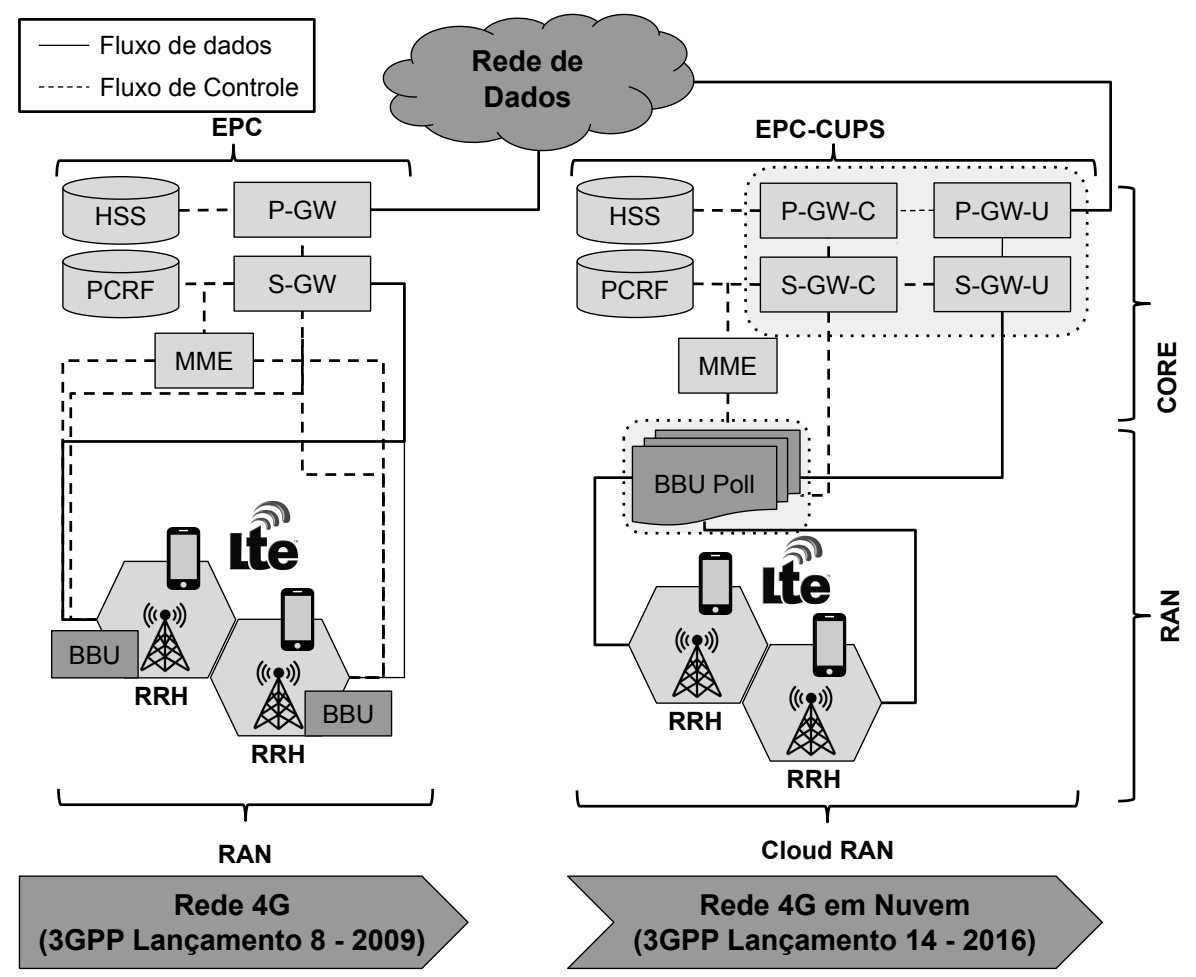

Figura 3.5. Evolução arquitetural do 4G.

\subsection{Redes 5G e posteriores}

A evolução das redes móveis celulares sempre buscou atingir um rádio onipresente de alta capacidade, i.e., com níveis cada vez mais baixos de latência e maior capacidade de transmissão. Em um primeiro momento, a chegada da 5G adiciona a essa evolução a abertura de um caminho para tecnologias de IoT e comunicação inteligentes, explorando novas formas de conectividade entre veículos e infraestrutura (V2I - Vehicle-to-Infrastructure), veículo para veículo (V2V - Vehicle-to-Vehicle), conexão pessoa-a-pessoa (D2D - Deviceto-Device). Entretanto, essa evolução significativa e amplamente publicizada esconde a verdadeira revolução de $5 \mathrm{G}$, a qual descrevemos a seguir.

5G está sendo desenvolvida para inovação e evolução dos sistemas celulares. Essa 
geração é a mais dinâmica e flexível das redes celulares já projetada, fazendo uso extensivo de aplicativos e núcleo nativos em nuvem. Além disso, 5G tem potencial para ser moldada durante seu desenvolvimento, a fim de absorver novos saltos evolutivos dentro do mesmo padrão. Essa característica visa acompanhar a evolução exponencial das principais tecnologias, como inteligência artificial e automação, por exemplo. Para atingir essa maturidade, $5 \mathrm{G}$ foi projetada para fazer amplo uso da virtualização de serviços e microsserviços. Em um primeiro momento, 5G será operada por uma rede híbrida, na qual a convergência, a integração e a coexistência com sistemas legados é inevitável. Entretanto, no futuro, o sistema $5 \mathrm{G}$ será predominantemente composto de funções de redes virtuais.

A 3GPP projetou a rede de acesso por rádio 5G (NG-RAN - Next Generation Radio Access Network) e o núcleo 5G baseado em serviços (SBA - Service-Based Architecture) de forma independente e interoperável. Baseado nesse projeto, trata-se de uma abordagem diferente das gerações anteriores de redes móveis, nas quais RAN e núcleo foram projetados de maneira acoplada. Assim, a partir da 5G, o padrão prevê a integração de elementos de diferentes gerações em diferentes configurações. Considerando especificamente a transição entre $4 \mathrm{G}$ e $5 \mathrm{G}$, durante a fase inicial da definição da arquitetura 5G, foi definida uma terminologia para identificar as diferentes variantes que surgiram da integração entre rede de acesso e núcleo. As opções definidas estão ilustradas na Figura 3.6.

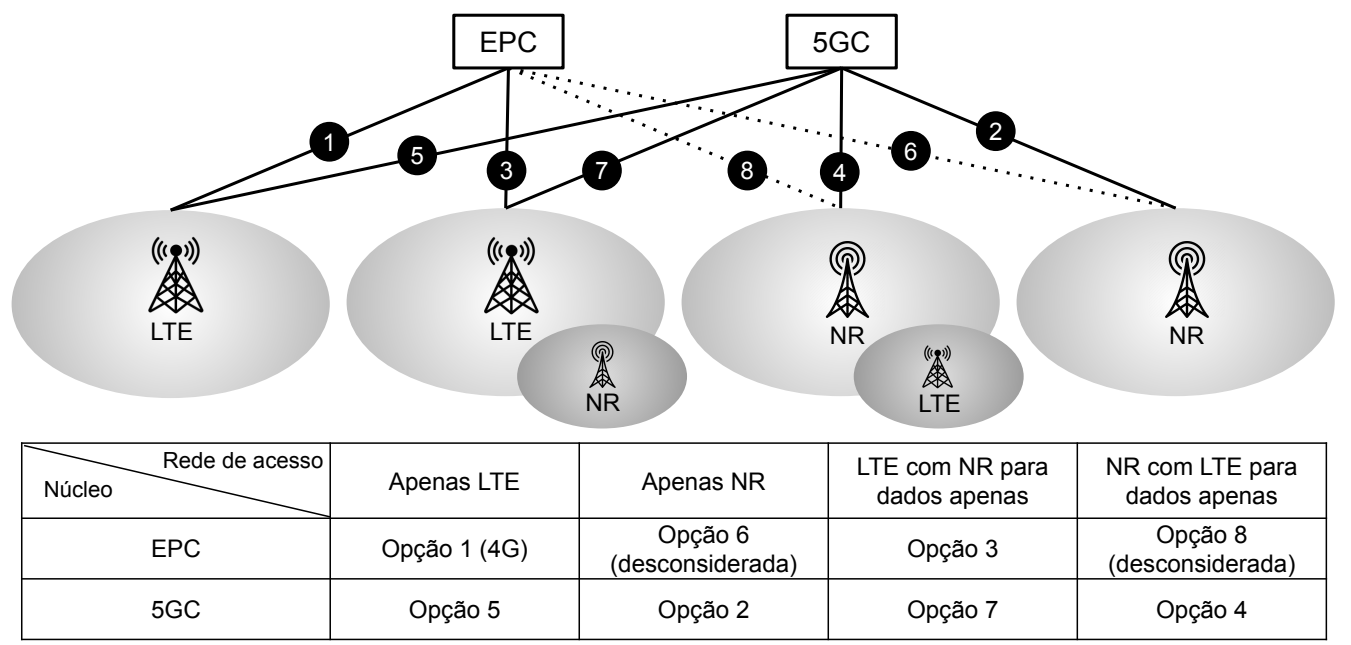

Figura 3.6. Opções definidas durante a fase inicial da definição do sistema 5G.

Na Figura 3.6, a opção 1 corresponde ao sistema 4G existente e especificada em lançamentos anteriores da 3GPP. As opções 6 e 8 foram desconsideradas, pois introduziriam muitas limitações ao NR (New Radio) de 5G, para fornecer compatibilidade retroativa com o EPC. Embora as opções 2, 3, 4, 5 e 7 tenham sido consideradas nos trabalhos de especificação, foi definido que as prioridades seriam as opções 2 e 3. Assim, o Lançamento 15 da 3GPP introduziu as arquiteturas Não-Autônoma (NSA - Non-Stand Alone), opção 3, e Autônoma (SA - Stand-Alone), opção 2.

A arquitetura NSA foi proposta em maio de 2018 e seis meses depois, 3GPP apresentou as especificações para a arquitetura SA. NSA é uma forma rápida para prover conectividade de alta vazão de dados, pois permite o aproveitamento dos ativos de rede 
existentes, sem a necessidade de implantar um novo sistema completo de ponta-a-ponta para a rede 5G, i.e., uma arquitetura de transição da 4G para 5G. Na NSA, somente a tecnologia de rádio precisa ser atualizada. No entanto, para melhor explorar a capacidade da 5G, visando novos serviços, uma nova arquitetura independente do sistema $4 \mathrm{G}$ existente faz-se necessária. SA é considerada a arquitetura $5 \mathrm{G}$ definitiva, incluindo as melhorias na transmissão de rádio, juntamente com núcleo $5 \mathrm{G}$ nativo em nuvem. As duas arquiteturas propostas no Lançamento 15 da 3GPP estão ilustradas na Figura 3.7 e são discutidas nas subseções seguintes.

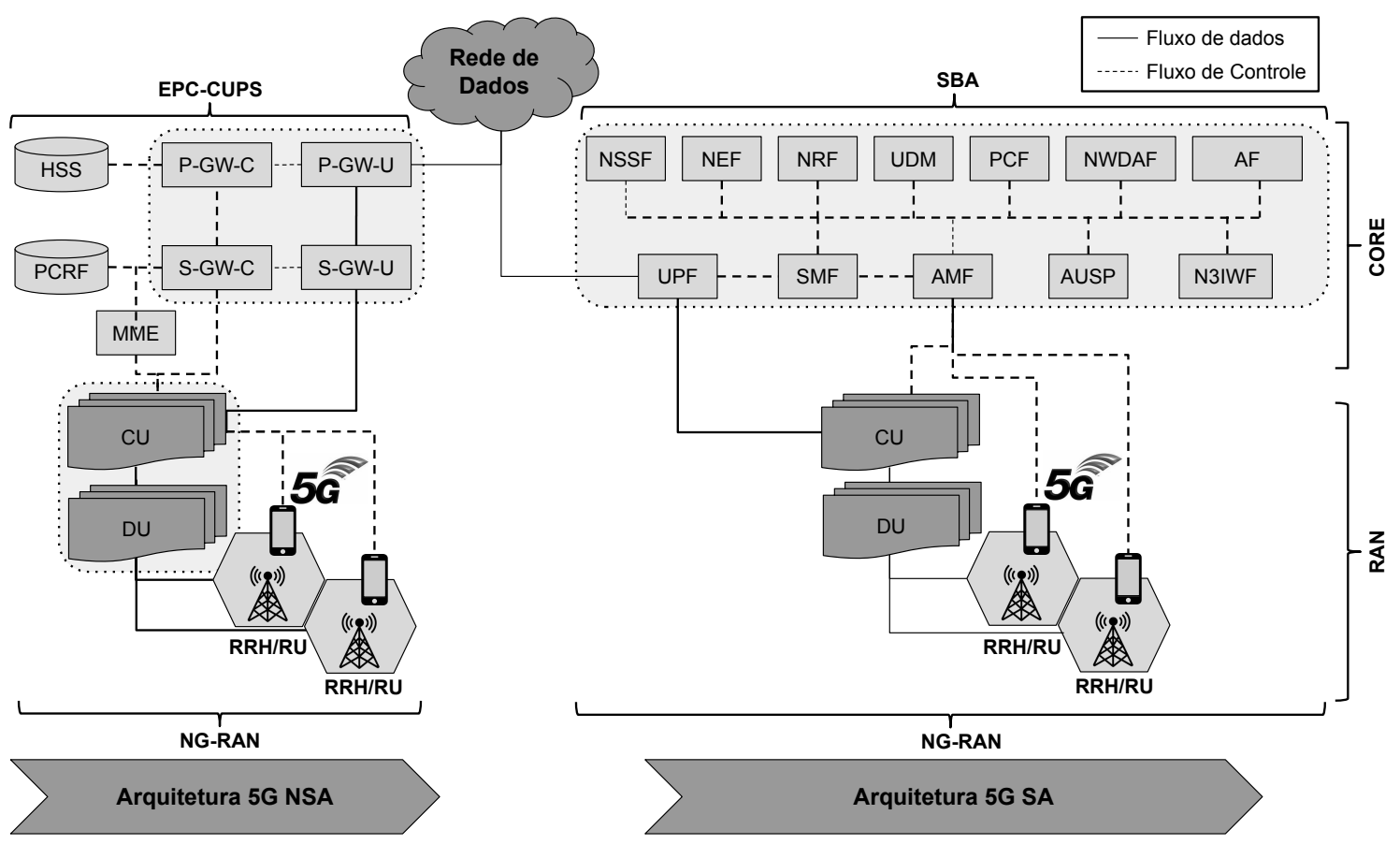

Figura 3.7. Arquiteturas 5G: Não-Autônoma (à esquerda) e Autônoma (à direita).

\subsubsection{Arquitetura 5G Não-Autônoma (NSA - Non-Stand Alone)}

A arquitetura NSA, também conhecida como EN-DC (E-UTRAN-NR Dual Connectivity), atende a filosofia da indústria de telecomunicações de introduzir novas tecnologias da maneira mais rápida e menos disruptiva. Embora as motivações sejam claras, é importante destacar algumas desvantagens da arquitetura NSA. Nessa arquitetura, a nova interface de rádio (NR) pode ser implantada apenas onde já existir cobertura 4G/LTE, indicando a ausência de autonomia da arquitetura, conforme sugerido pelo nome NSA. Além disso, as funcionalidades de rede disponíveis estão limitadas ao que é oferecido por LTE/EPC. Desta forma, várias novidades introduzidas no sistema 5G não estão disponíveis, tais como: fatiamento de rede, tratamento de QoS, flexibilidade na computação de borda e a extensibilidade geral do núcleo 5G, para incluir novas aplicações em um ambiente similar ao de nuvem tradicional.

O projeto da arquitetura NSA se focou principalmente em permitir que pelo menos duas inovações da 5G fossem introduzidas: (i) aumento sensível da capacidade de largura 
de banda e vazão da rede, e (ii) maior flexibilidade nas funções do plano de usuário fornecidas pelos GWs (S-GW e P-GW) do núcleo EPC. Conforme ilustrado na Figura 3.8, a separação entre os planos de controle e dados nos GWs, e a conexão dupla através de LTE e NR são duas características importantes introduzidas na arquitetura NSA. Basicamente, foram introduzidos três conjuntos de tecnologias para implementar essas características: (i) DEdicated CORE networks (DECOR) e enhanced DECOR), (ii) Control and User Plane Separation (CUPS) e (iii) NR como RAT (Radio Access Technology) secundária. A seguir, descrevemos brevemente essas tecnologias.

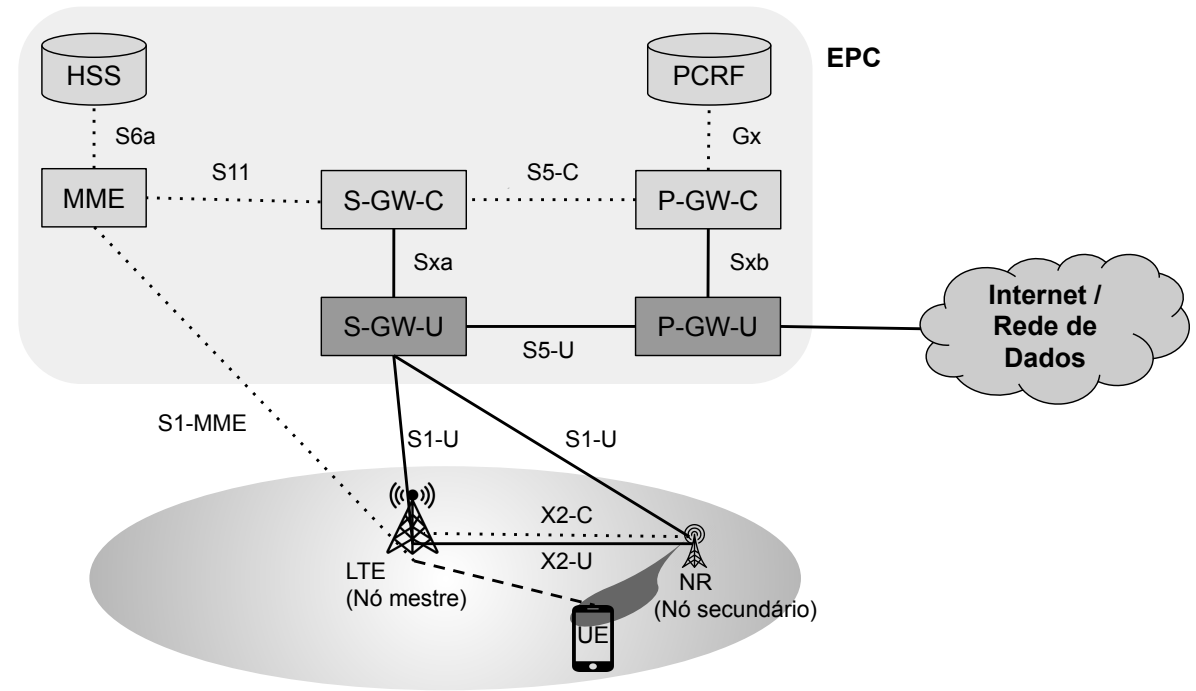

Figura 3.8. Arquitetura NSA, com destaque para a separação entre controle e dados nos GWs e a conexão dupla (LTE e NR).

\section{DEdicated CORE networks (DECOR) e enhanced DECOR)}

Um operador de rede é reconhecido pelo seu identificador PLMN (Public Land Mobile Network), que originalmente corresponde a um núcleo de rede móvel. No entanto, ainda em 4G, houve uma demanda significativa por flexibilizar essa abordagem e permitir que um único operador pudesse instanciar múltiplos núcleos e também direcionar cada usuário para o núcleo adequado de acordo com o serviço necessário. Antes da introdução de eDECOR, a separação de núcleos era possível apenas utilizando diferentes identificadores de PLMN, ou seja, instanciando redes de núcleo independentes. Uma solução alternativa era utilizar APNs (Access Point Names) diferentes para direcionar os usuários para várias redes de serviço, que estavam associados a diferentes entidades do plano de usuário, em especial, P-GWs. Ambas as abordagens, ilustradas na Figura 3.9(a), eram pouco flexíveis.

Através da introdução de eDECOR, um operador pode implantar múltiplas redes de núcleo dedicadas (DCNs - Dedicated Core Networks) dentro de uma PLMN com cada DCN consistindo de um ou múltiplos nós da rede de núcleo (e.g., apenas MME, MME com GWs, MME, GWs e PCRF). Cada DCN pode ser dedicada a servir um tipo diferente de UE, separando certos tipos de tráfego em nós da rede de núcleo específicos e, se necessários, os ajustando diferentemente do restante dos nós da rede de núcleo. 


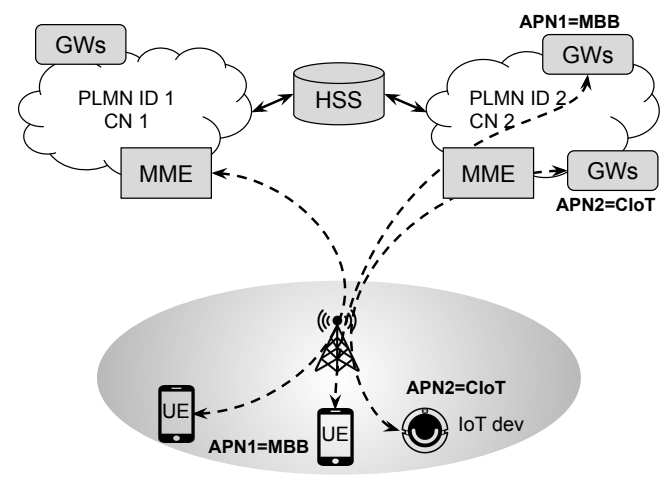

(a) pre-DECOR

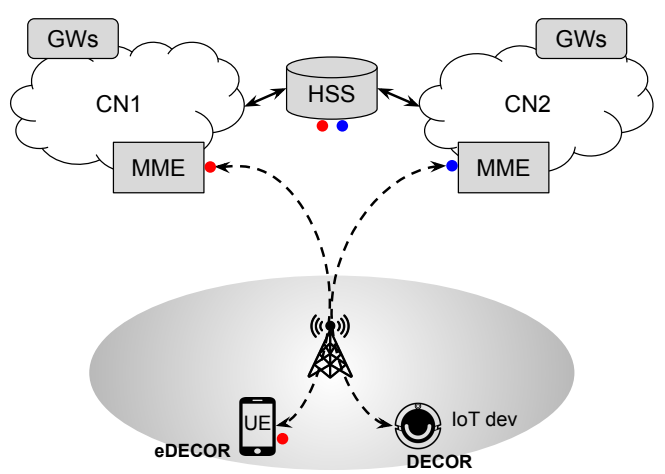

(b) DECOR e eDECOR

Figura 3.9. Exemplo de uma configuração pre-DECOR, usando APNs, em comparação com o uso de DECOR e eDECOR.

Com DECOR, as informações necessárias para identificar como encaminhar o tráfego do usuário são obtidas pela MME apenas no HSS, enquanto que eDECOR exige que o UE forneça informações específica (i.e., a DCN desejada) para facilitar a seleção rápida e ótima da rede de núcleo dedicada. A Figura 3.9(b) ilustra o uso de DECOR (com informações inicialmente apenas no HSS, representadas pelo círculo azul) e eDECOR (com informações também no UE, representadas pelos círculos vermelhos) para acessar diferentes DCNs.

De fato, eDECOR pode ser considerada precursora da implantação do conceito de fatiamento de rede, já introduzindo algumas características similares como diferenciação de QoS e instanciação de múltiplos nós da rede de núcleo para atender cada serviço. Por outro lado, fatiamento de rede é um conceito mais avançado que permite o operador da rede móvel realizar o fatiamento fim-a-fim, desde a parte do rádio frequência, passando por toda a rede de acesso e incluindo todo o núcleo. Fatiamento de rede deve permitir criar fatias de recursos que são isoladas parcial ou totalmente, física ou logicamente.

\section{Control and User Plane Separation (CUPS)}

A funcionalidade de separação entre planos de controle e de usuário (CUPS) surgiu da necessidade de dimensionar independentemente as funções de plano de usuário e de controle da rede (de pacotes) do núcleo para o gerenciamento de sessão e os serviços de dados. Antes da introdução de CUPS, não era possível implantar componentes de GW apenas com função (de dados) de usuário ou dimensionar independentemente, de maneira padronizada, as partes de plano de controle e de plano de usuário. A necessidade dessa separação tornou-se bastante clara à medida que as operadoras começaram a considerar os impactos em sua rede de recursos internos, como IoT (de banda estreita), banda larga móvel (Mobile Broadband - MBB), e também o crescimento de serviços OTT (OverThe-Top) baseados na Internet, como vídeo em fluxo armazenado, compartilhamento de conteúdo e comunicação em mídia social. Conforme ilustrado na Figura 3.10, CUPS pode ser aplicada aos seguintes elementos do EPS: S-GW, P-GW e função de detecção de tráfego (TDF - Traffic Detection Function).

Como pode ser visto na Figura 3.10, o plano de controle e o plano de usuário 


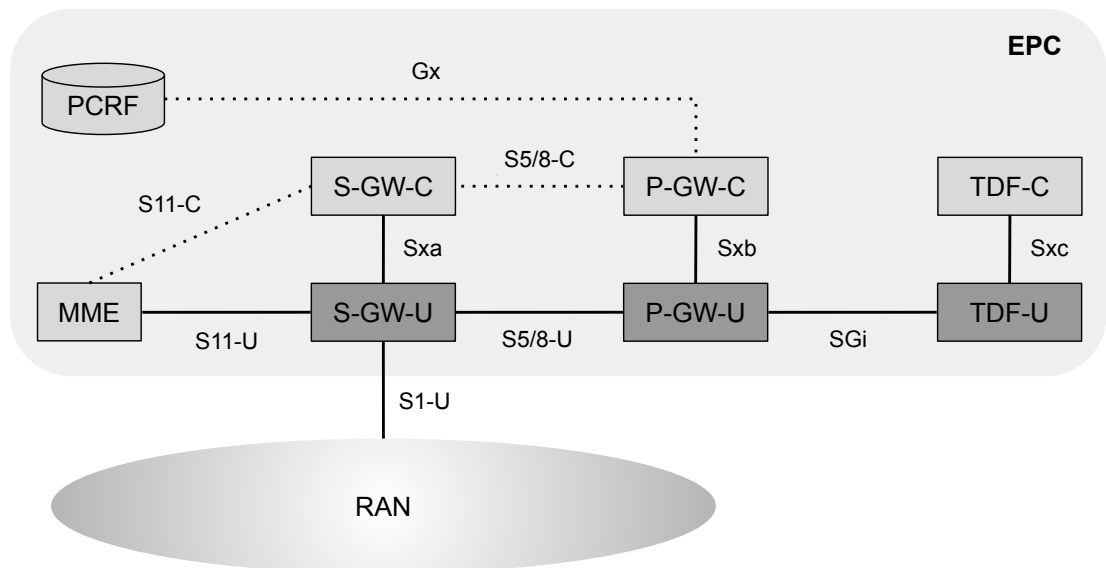

Figura 3.10. Arquitetura básica do EPC com a separação entre os planos de controle e de usuário.

de cada elemento (S-GW, P-GW e TDF) utiliza uma interface Sx (a, b e c, respectivamente) para realizar a comunicação necessária. A interface $\mathrm{Sx}$ oferece procedimentos para estabelecimento, modificação e encerramento, com intuito de fornecer suporte para as operações de plano de controle e plano de usuário entre os componentes de cada nó separado. A 3GPP definiu o PFCP (Packet Forwarding Control Protocol) para suporte a essas funcionalidades em Sx e esse protocolo também foi adotado em sistemas 5G.

Utilizando S-GW e P-GW como exemplos, é interessante destacar algumas características de projeto da CUPS. Desde o início, ficou evidente que nem todos os cenários exigiriam a separação entre os planos (de controle e de usuário) e que os cenários mais comuns de implantação teriam que contemplar a coexistência de nós com e sem a separação em uma única rede. Assim, foi definido que a separação entre os planos não deveria ter nenhum impacto em outros componentes do núcleo, como MME, PCRF, sistema de cobrança/tarifação e sistema de gerenciamento de assinaturas. Além disso, CUPS também foi projetada para não impactar nenhum procedimento ou protocolo que envolvesse UEs e elementos da RAN. Como consequência, outros elementos da rede não têm conhecimento se o S-GW e o P-GW com os quais interagem possuem ou não planos de controle e de usuário separados.

\section{NR como tecnologia de rádio de acesso secundária}

A conectividade dupla (DC - Dual Connectivity) da arquitetura NSA permite que o UE e a RAN possam receber e transmitir dados por duas estações-base simultaneamente. Desta forma, a DC provê a capacidade de utilizar recursos de rádio fornecidos por dois grupos de células operando independentemente, mas conectados a um único núcleo. No contexto NSA, a principal motivação da conectividade dupla é aumentar a taxa de transferência do usuário, mas também é possível fornecer maior robustez de mobilidade e oferecer suporte a balanceamento de carga entre os nós da RAN. Inicialmente, o conceito de conectividade dupla foi introduzido para o EPS com dois grupos de células, ambos fornecendo recursos E-UTRAN. A BS que o UE se conecta primeiro (e a partir da qual toda a sinalização em direção ao núcleo é realizada) é conhecida como nó mestre e possui 
a localização onde UE está associada. Quando o UE atingir o estado conectado, o nó mestre pode solicitar outra BS (i.e., nó secundário) para descarregar o tráfego de dados. Posteriormente, a solução evoluiu para suportar múltiplas tecnologias de rádio (MR-DC Multi-Radio DC), sendo EN-DC a variante que combina as tecnologias E-UTRAN e NR.

O requisito de flexibilidade do espectro foi um fator determinante para a adoção de tecnologias baseadas em OFDM em LTE para 4G e continua a ser um fator importante para o planejamento e as implantações de NR para 5G. Ao longo de 3G e 4G surgiu da necessidade de alocações em diversas bandas de frequência do espectro, diferentes larguras de banda de operação, múltiplos esquemas duplexação e esquemas de acesso múltiplo. No entanto, a largura e diversidade do espectro utilizado no NR representam uma das caraterísticas mais peculiares da 5G. O NR suporta um espectro grande e diversificado de $410 \mathrm{MHz}$ a 52,6 GHz (e até $100 \mathrm{GHz}$ em lançamentos futuros). Além disso, NR pode utilizar larguras de banda de $5 \mathrm{MHz}$ a 3,2 GHz, suportando TDD (Time Division Duplex) e FDD (Frequency Division Duplex), assim como portadoras suplementares para enlaces de descida (SDL supplementary downlink) ou subida (SUL - supplementary uplink). Nesse contexto, a 3GPP definiu no Lançamento 15 duas faixas de frequência (Frequency Range): FR1 (410 MHz - $7125 \mathrm{MHz})$ e FR2 (24250 MHz - 52600 MHz). A FR2, também conhecida como faixa de ondas milimétricas, é a que oferece a maior capacidade, porém possui características físicas distintas da FR1, além de apresentar o maior desafio para implantação e uso em 5G. A seguir, apresentamos algumas informações adicionais sobre ondas milimétricas, as quais ainda são um assunto de significativo interesse acadêmico [31, 32].

A faixa de ondas milimétricas pode proporcionar comunicações com taxas na ordem de Gigabits e, por isso, é bastante atrativa para redes móveis. Entretanto, essas ondas impõem grandes desafios no projeto, implementação e operação dos sistemas, pois sofrerem maior degradação e atenuação na propagação, além de ser mais suscetíveis a bloqueios físicos e absorção atmosférica. Por outro lado, com o desenvolvimento de elementos de antenas cada vez menores, é possível habilita a construção de conjuntos de antenas para o emprego de MIMO massivo e formação de feixe (beamforming), que auxilia no tratamento dos problemas de propagação e melhora sensivelmente o reuso de frequência. No entanto, a formação/manutenção de feixe consome um tempo não negligenciável e seu aperfeiçoamento tem sido tema de vários trabalhos [33, 34]. Além disso, o problema se torna notadamente difícil quando é considerada a mobilidade dos usuários. Uma das estratégias da 3GPP para minimizar essas limitações é utilizar a arquitetura 5G Autônoma, como será apresentada na próxima subseção.

\subsubsection{Arquitetura 5G Autônoma (SA - Stand Alone)}

$\mathrm{Na}$ arquitetura SA, o núcleo EPC é substituído pelo núcleo SBA (apresentado detalhadamente na Seção 3.5), permitindo a utilização de um conjunto de funções de redes virtuais que fornecem serviços para outras funções da arquitetura ou, até mesmo, para aplicações de usuários finais. Desta forma, a arquitetura SA consolida o conceito de dissociação de dados e controle, permitindo o posicionamento flexível e sem estado de funções virtuais nos diferentes segmentos de rede que compõem um sistema 5G. Por exemplo, esses segmentos podem ser vistos como edge, fog e nuvem, ou ainda, especificamente na RAN, podemos encontrar segmentos como fronthaul, midhaul, backhaul. 
Um grande avanço da arquitetura SA é seu direcionamento para o desenvolvimento de funções de redes virtuais baseado no modelo nativo da nuvem, i.e., (Cloud Native). Essa abordagem refere-se a como as funções de redes virtuais são criadas e implantadas de maneira flexível, utilizando amplamente o conceito de computação em nuvem para desenvolver, implantar e gerenciar serviços. Por exemplo, dentro dessa abordagem, o conceito de microsserviços pode ser utilizado para a implantação e expansão de um sistema 5G, alinhado as evoluções ágeis da tecnologia da informação. Um dos objetivos de utilizar microsserviços é poder decompor os componentes em funções especializadas, com baixa granularidade, para tornar o serviço leve e com alta capacidade de compartilhamento. Esse objetivo encaixa-se perfeitamente na necessidade de suportar os cenários de comunicação eMBB, mMTC e URLLC, uma vez que oferece modularidade, reutilização de funções e interoperabilidade com redes heterogêneas. Além disso, a introdução de microsserviços e interfaces para acessá-los simplifica os processos de atualização e manutenção de sistemas $5 \mathrm{G}$, reduzindo o custo da operação e acelerando a introdução de novos serviços.

A implantação da arquitetura SA de forma plena apresenta alguns desafios. Por exemplo, historicamente as gerações de redes celulares são fortemente baseadas no contexto de sessões dos UEs, caracterizando uma arquitetura baseada em estado. Por outro lado, sistemas baseados no modelo de computação em nuvem nativa, possuem como característica fundamental a arquitetura sem estado, onde os contextos de seus estados são salvos em banco de dados. Por exemplo, o núcleo SBA introduz a função de armazenamento de dados não estruturada (UDFS - Unstructured Data Storage Function) para controlar o contexto das funções de redes, como pode ser observado na Figura 3.11 . Essa característica permite usufruir de benefícios como elasticidade e gerenciamento dinâmico dos microsserviços em redes móveis. Um dos grandes desafios da $5 \mathrm{G}$ é projetar e desenvolver componentes de software baseados originalmente em estados, através da pilha de protocolos especificados pela 3GPP, para microsserviços sem estados, usufruindo plenamente dos benefícios da computação em nuvem nativa.
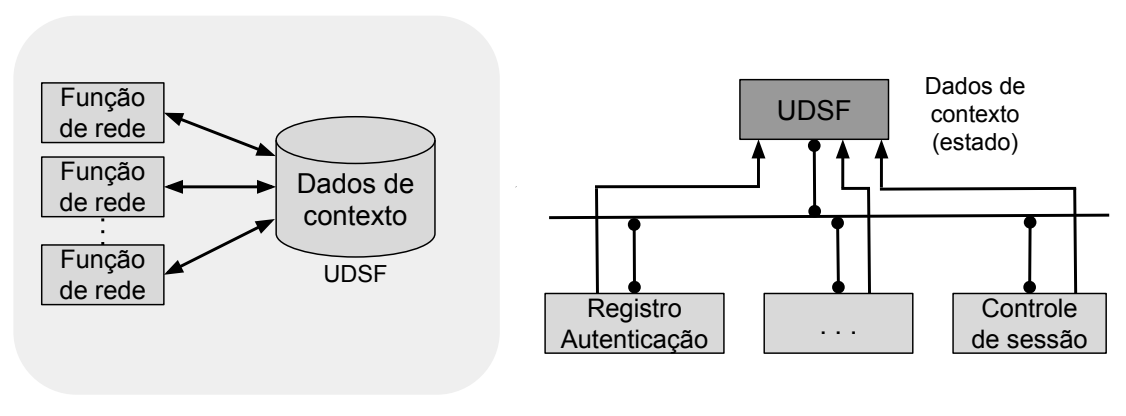

Figura 3.11. Função de dados de contexto da arquitetura SA.

$\mathrm{Na}$ arquitetura SA, a característica fundamental é que os elementos são definidos como funções de rede, as quais fornecem serviços a outras funções, ou qualquer outro consumidor autorizado, mediante interfaces de programação. Desta forma, a arquitetura fornece ampla modularização e reusabilidade em um completo isolamento entre o plano de dados e o plano de controle. Devido a essa alta modularização, a eventual migração 
da arquitetura NSA para SA deve ser imperceptível para o usuário final. Além disso, vale ressaltar que a NSA e a SA não são propostas que competem, mas sim um caminho evolutivo para adoção das inovações introduzidas por 5G. A intenção é começar com NSA e migrar gradualmente para SA ao longo do tempo, em especial para operadores que já tenham investimento expressivo em redes 4G. Por algum tempo, NSA e SA devem coexistir e várias abordagens são possíveis. A Figura 3.12 ilustra uma solução potencial proposta pela Samsung [35], na qual surge uma arquitetura intermediária, utilizando um núcleo comum.

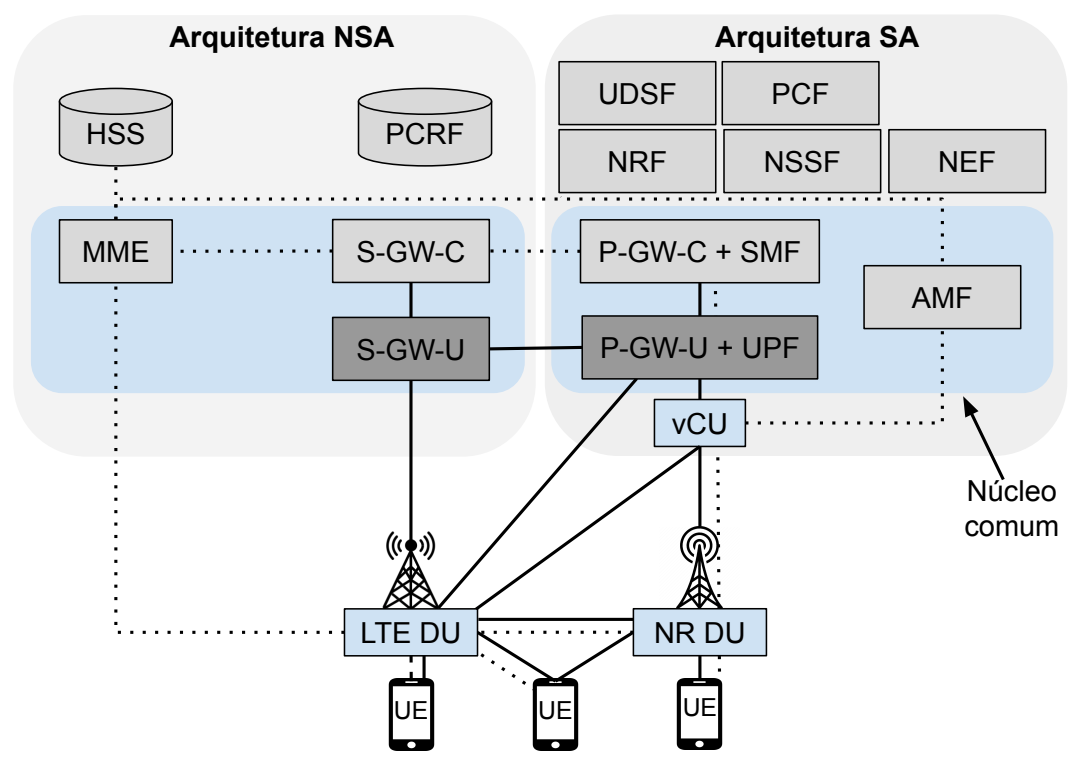

Figura 3.12. Proposta para coexistência das arquiteturas NSA e SA.

\subsubsection{Pós-5G}

Embora muitos países, como o Brasil, ainda estejam discutindo e se preparando para a implantação das redes 5G, 2019 é o ano em que a adoção efetiva começou em vários países. Alemanha, China, Coreia do Sul, Estados Unidos, Finlândia e Reino Unido são exemplos de países que já estão implantando, testando e/ou efetivamente utilizando redes 5G. Como esperado, a comunidade científica já começou a investigar questões sobre os limites das redes 5G, sobre aplicações (novas ou já existentes) que se beneficiariam de comunicação sem fio, mas não seriam devidamente atendidas por essas redes, sobre tecnologias que precisam evoluir ou serem criadas para atender novas potenciais demandas, dentre vários outros temas [36, 37]. Embora não seja possível prever precisamente como será a próxima geração de redes móveis sem fio e quais aplicações justificarão sua adoção, alguns temas são recorrentes nas discussões e investigações iniciais, sendo improvável que não sejam parte da evolução das redes 5G. Dentre esses temas, estão a alocação eficiente de recursos diversos em redes sem fio (e.g., bandas sub-6GHz, ondas milimétricas e, futuramente, bandas em THz [38]), amplo uso de aprendizado de máquina e inteligência artificial, e aplicações que não são atendidas por redes 5G, tais como realidade estendida multissensorial e interações cérebro-computador sem fio. 
Redes 5G tornaram notória a necessidade de considerar múltiplos tipos de recursos sem fio, além das tradicionais bandas licenciadas sub-3GHz. Em redes 5G, é possível utilizar a banda de $3,5 \mathrm{GHz}$, banda não-licenciada de $5 \mathrm{GHz}$, ondas milimétricas e comunicações D2D (Device-to-Device). Adicionalmente, já há recursos Multi-access Edge Computing (MEC) que permitem melhorar a comunicação dos dispositivos através de várias estratégias como armazenamento em cache, descarregamento de processamento, uso de informações de contexto, alocação de largura de banda, dentre outras. No entanto, uma oferta confiável de alta banda usando ondas milimétricas (posteriormente da banda de $\mathrm{THz}$ ) em cenários com mobilidade é um desafio que dificilmente será superado em larga escala nas redes 5G. Devido a alta direcionalidade dos feixes de ondas milimétricas, é necessário que o alinhamento entre as antenas de dispositivos móveis e de BSs seja refeito com alta regularidade. Atualmente, isso significa rupturas na comunicação, mas à medida que cresce o número de BSs (tanto de ondas milimétricas, quanto de sub-6GHz) é possível mitigar o problema através da alocação adequada dos recursos. No entanto, essa alocação é complexa, pois envolve múltiplos dispositivos, múltiplas BSs, recursos diversos e deve ser realizada de maneira dinâmica em curtas escalas de tempo para atender a mobilidade dos usuários [39]. Baseado nesse contexto, existe um grande volume de dados que precisa ser processado rapidamente para tomada de decisão a respeito da alocação de recursos.

Além de modelos de otimização, o contexto descrito também pode fazer amplo uso de técnicas de aprendizado de máquina e inteligência artificial. De fato, essas técnicas foram inicialmente exploradas na $4 \mathrm{G}$ através do conceito de redes auto-organizáveis (SON - Self-Organizing Networks) [40]. Em redes 5G, aprendizado de máquina e inteligência artificial devem ter um uso mais amplo, dado o grande volume de dados a ser manipulado e a maior complexidade da rede [36]. No entanto, uma adoção ampla é prevista apenas após a consolidação das redes $5 \mathrm{G}$ e na próxima geração das comunicações móveis [41]. Além do aumento no volume de dados e da complexidade da infraestrutura, as evoluções recentes nas técnicas de aprendizado de máquina e inteligência tem motivado sua utilização mais ampla. Entretanto, para que soluções baseadas em inteligência artificial sejam massivamente empregadas em redes de comunicação, é importante que elas sejam construídas sob a perspectiva Inteligência Artificial Explicável (XIA - Explainable Artificial Intelligence) [42]. Entender o comportamento de soluções baseadas em inteligência artificial é um requisito importante para sua adoção em infraestruturas de comunicação.

As redes 5G estão introduzindo novas tecnologias de comunicação para atender uma ampla gama de aplicações e serviços. Por exemplo, eMBB, URLLC e mMTC fazem parte do sistema $5 \mathrm{G}$ para oferecer suporte a aplicações como vídeo $4 \mathrm{~K}$ e $8 \mathrm{~K}$, carros autônomos, realidade virtual e aumentada e Indústria 4.0. No entanto, já estão surgindo aplicações que não são devidamente atendidas por redes $5 \mathrm{G}$, tais como realidade estendida multissensorial, telepresença holográfica, interações cérebro-computador sem fio e sistemas autônomos e robóticos conectados [36, 37]. Em geral, essas aplicações apresentam novos requisitos de QoS que podem motivar a introdução de novas classes de serviço como comunicação de baixa latência confiável de banda larga móvel (MBRLLC - Mobile Broadband Reliable Low Latency Communication) e comunicações maciças de baixa latência ultra confiáveis (mURLLC - massive URLLC). Por outro lado, para explorar 
de maneira mais eficiente os recursos disponíveis, é importante investigar e caracterizar adequadamente a demanda das aplicações, levando em conta não apenas requisitos de QoS, mas também requisitos de qualidade de experiência dos usuários (QoE - Quality of Experience) e de qualidade de experiência física (QoPE - Quality of Physical Experience) [36, 43].

\subsection{Rede de acesso por rádio}

Uma RAN é responsável por gerenciar a interface aérea para manter uma grande quantidade de usuários conectados. Desta forma, a RAN necessita eficientemente gerenciar o espectro de Rádio Frequência (RF), realizando uma série de tarefas, tais como gerenciamento de recursos de rádio, controle de mobilidade da conexão, alocação dinâmica de recursos para os equipamentos dos usuários, compressão e segurança de camada física, gerenciamento de sessão e fluxo de qualidade de serviço, dentre outras funções.

Originalmente, em uma RAN tradicional, o front-end de RF e as funcionalidades de processamento de banda-base eram integradas dentro de uma BS. O módulo da antena estava localizado a poucos metros do módulo de rádio, conectado com um cabo coaxial e apresentando altas taxas de perdas de transmissão. Essa arquitetura foi popular nas redes móveis de $1 \mathrm{G}$ e $2 \mathrm{G}$. Nos últimos anos, o front-end de RF foi desacoplado do módulo de processamento de banda-base, permitindo os operadores móveis substituírem esse módulo de acordo com a demanda dos usuários. Esse desacoplamento arquitetônico permitiu avanços de centralização e virtualização no módulo de processamento de bandabase e no front-end de RF. A seguir, a Subseção 3.4.1 apresenta a evolução do conceito de centralização da arquitetura de banda-base e a Subseção 3.4 .2 apresenta a virtualização da RAN, que iniciou na $4 \mathrm{G}$ e continua evoluindo em redes $5 \mathrm{G}$.

\subsubsection{Centralização da RAN}

A alta taxa de transmissão de dados entre o domínio digital de processamento de banda-base e o domínio analógico do front-end de RF com a antena exige um barramento de alta largura de banda que conecta esses dois domínios. Essa exigência limitou, por muitos anos, o projeto de BS a componentes de hardware especializados com um barramento de alto desempenho conectando esses dois domínios. Essa limitação foi superada com a utilização de fibra ótica nesse barramento, reduzindo a perda de dados e aumentando a distância entre os domínios conectados. Nas gerações 3G/4G, especialmente a partir do Lançamento 8 da 3GPP, o processamento da banda-base passou a ser implementado em BaseBand Units (BBUs), i.e., um hardware dedicado e especializado que implementa uma RAT, enquanto a Remote Radio Head (RRH) integra ofront-end de RF com a antena. Na Figura 3.13, é ilustrada a evolução da arquitetura RAN de 2G para 3G/4G.

Em 3G/4G, o front-end de RF e o processamento de banda-base são claramente separados, como pode ser visto no lado direito da Figura 3.13. A RRH, também chamada de Unidade de Rádio, possui uma interface de fibra ótica e realiza a conversão analógica/digital e vice-versa, amplificação da potência e filtragem do sinal. O processamento de banda-base, agora realizado na BBU, é isolado e independente da unidade de rádio. Essa arquitetura é considerada descentralizada, uma vez que a BBU realiza sua operação separadamente da unidade de rádio. Avanços recentes impulsionaram a largura de 


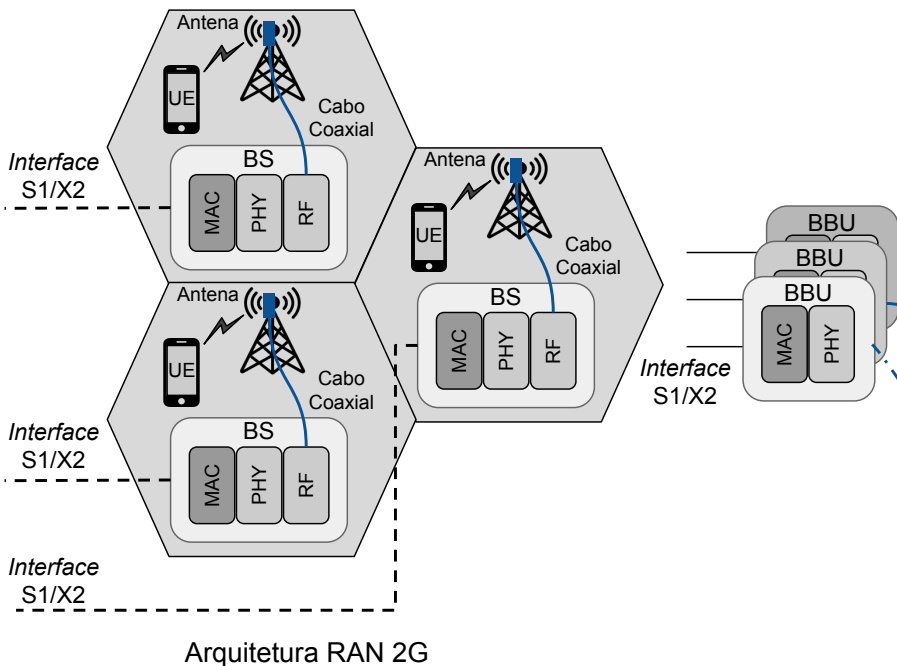

Arquitetura RAN 2G

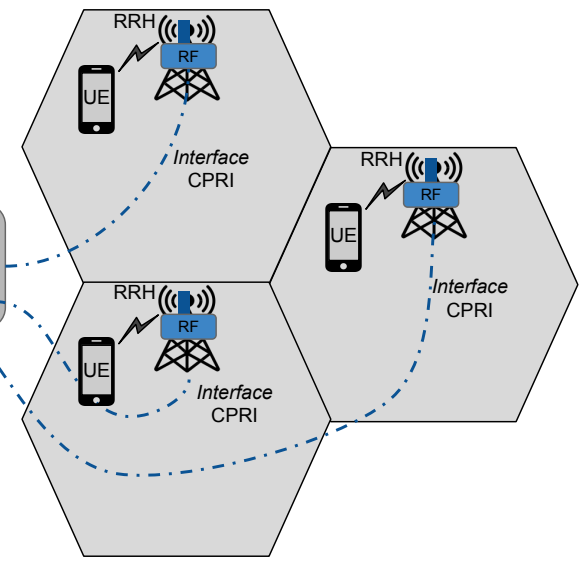

Arquitetura RAN 3G/4G

Figura 3.13. Evolução das arquiteturas RAN.

banda das fibras óticas permitindo incorporar arquiteturas baseadas em nuvem na rede de acesso por rádio (C-RAN - Cloud Radio Access Network). Nesse tipo de arquitetura, as BBUs podem estar localizadas em centro de dados (chamados arquiteturas de banda-base centralizadas), permitindo a redução de custo, através da manutenção centralizada e da elasticidade da computação em nuvem. Nessa nova configuração, as RRHs podem estar geograficamente separadas de um conjunto de BBUs por até aproximadamente $40 \mathrm{Km}$. Entretanto, é importante destacar que uma BBU é limitada ao processamento dos sinais de RRHs dentro de uma distância máxima, determinada de acordo com as restrições de atraso. Esse atraso é influenciado principalmente por três fatores: (i) distância entre BBU e RRH, (ii) condições do canal e (iii) capacidade de processamento disponível. Segundo Marotta et al. [44], a capacidade de processamento deve ser aumentada significativamente para RRHs que estão experimentando baixa Relação Sinal-Ruído (SNR - Signal-to-Noise Ratio) e estão a grande distância da BBU.

Os conceitos envolvidos em C-RAN têm chamado a atenção para a implementação inicial da 5G (Arquitetura NSA descrita na Subseção 3.3.1), principalmente considerando os benefícios de redução de custo e manutenção. Entretanto, BBUs são plataformas baseadas em hardware utilizando processadores de sinal digital especializados. Com objetivo de longo prazo, é fundamental substituir as BBUs baseadas em hardware especializados por software utilizando hardware de propósito geral, i.e., BBUs virtuais (vBBUs). Da mesma forma, podemos pensar em uma camada de virtualização de rádio que permita várias tecnologias de acesso heterogêneas coexistindo sobre uma mesma RRH. Essa coexistência usa técnicas inovadoras de processamento de banda-base para dividir e abstrair uma RRH em várias RRH virtuais (vRRHs). Essa visão de virtualização da RAN está alinhada com a Arquitetura SA (descrita na Subseção 3.3.2) proposta no Lançamento 15 da 3GPP, onde por exemplo, a utilização de vBBUs é um caso de uso de NFV (Network Functions Virtualization) para prover serviços em um sistema 5G. 


\subsubsection{Virtualização da RAN}

A virtualização da RAN (vRAN) tem recebido destaque em sistemas 5G, pois permite criar, gerenciar e configurar RANs dinamicamente, atendendo requisitos específicos de cada serviço. Além disso, o conceito de vRAN abre novos modelos de negócios em que provedores de serviços podem alugar vRANs dos provedores de infraestrutura. Nesse cenário, o provedor de infraestrutura controla todo o recurso físico, incluindo o espectro de RF, a RRH física, os recursos de hardware nos centros de dados (i.e., servidores com processamento, memória e armazenamento) e a rede física. Um provedor de serviço pode contratar de um provedor de infraestrutura uma ou mais vRANs, incluindo ao menos uma BS virtual, i.e., uma vRRH conectada a uma vBBU.

Isolamento, programabilidade e adaptabilidade são propriedades importantes para permitir a customização de vRAN para acomodar os diferentes serviços previstos para as redes 5G. Por exemplo, a combinação do fatiamento de BBU e RRH pode ser utilizada para instanciar uma vRAN fim-a-fim sobre uma infraestrutura física. Mais especificamente, o fatiamento e a virtualização podem ser implementados em uma BBU para permitir múltiplas vBBUs executarem sobre o mesmo hardware físico. Da mesma forma, uma RRH ou um conjunto delas podem suportar múltiplas vRRHs. Esses elementos aplicados para a vRAN, constituem os pilares para prover multi-serviços para as futuras redes móveis.

Um conjunto de vBBU e vRRHs pode ser executado em GPPs (General Purpose Processor), aproveitando as bibliotecas de processamento de sinal altamente otimizadas e aproveitando a evolução cada vez maior dos processadores, como maior poder de processamento e eficiência energética, como pode ser observado na Figura 3.14. Recentemente, o grupo de trabalho RAN3 da 3GPP [45] considerou a divisão de uma vBBU em duas novas entidades, denominadas Data Unit (DU) e Control Unit (CU). DU pode hospedar funções de tempo restrito da camada física, enquanto CU hospeda recursos de funções não críticas, como serviços de controle da camada MAC e superiores. A implementação da DU está prevista para cobrir uma área de 10 até $20 \mathrm{~km}$ de raio, enquanto a implementação da CU deve cobrir áreas de 100 a $200 \mathrm{~km}$.

No Lançamento 15 da 3GPP manteve-se o conceito de nuvem na RAN, mas o nome foi alterado para próxima geração de redes de acesso (NG-RAN - Next Generation Radio Acccess Network) utilizando uma interface chamada NG. Além disso, devido à interoperabilidade entre $4 \mathrm{G}$ e $5 \mathrm{G}$, DU e CU foram renomeadas para gNB-DU e gNB-CU. Uma gNB é responsável por uma série de tarefas, tais como gerenciamento de recursos de rádio, controle de mobilidade da conexão, alocação dinâmica de recursos aos equipamentos dos usuários, compressão e segurança de camada física, gerenciamento de sessão e fluxo de qualidade de serviço, dentre outras funções. Assim, a pilha de protocolos da gNB é detalhada considerando PHY, MAC, RLC, PDCP, RRC, etc.

A virtualização também introduziu a possibilidade de divisão da pilha de protocolos da gNB em funções de rede. Nesse contexto, 3GPP propôs oito opções para a divisão funcional entre as unidades centralizadas e distribuídas [45], considerando requisitos de transporte, em especial, vazão e latência. González-Día et al. [46] avaliaram, em um ambiente experimental, três opções de fatiamento referentes ao fronthaul, além de uma opção da unidade de dados do backhaul, como ilustrado na Figura 3.15. As oito opções de 


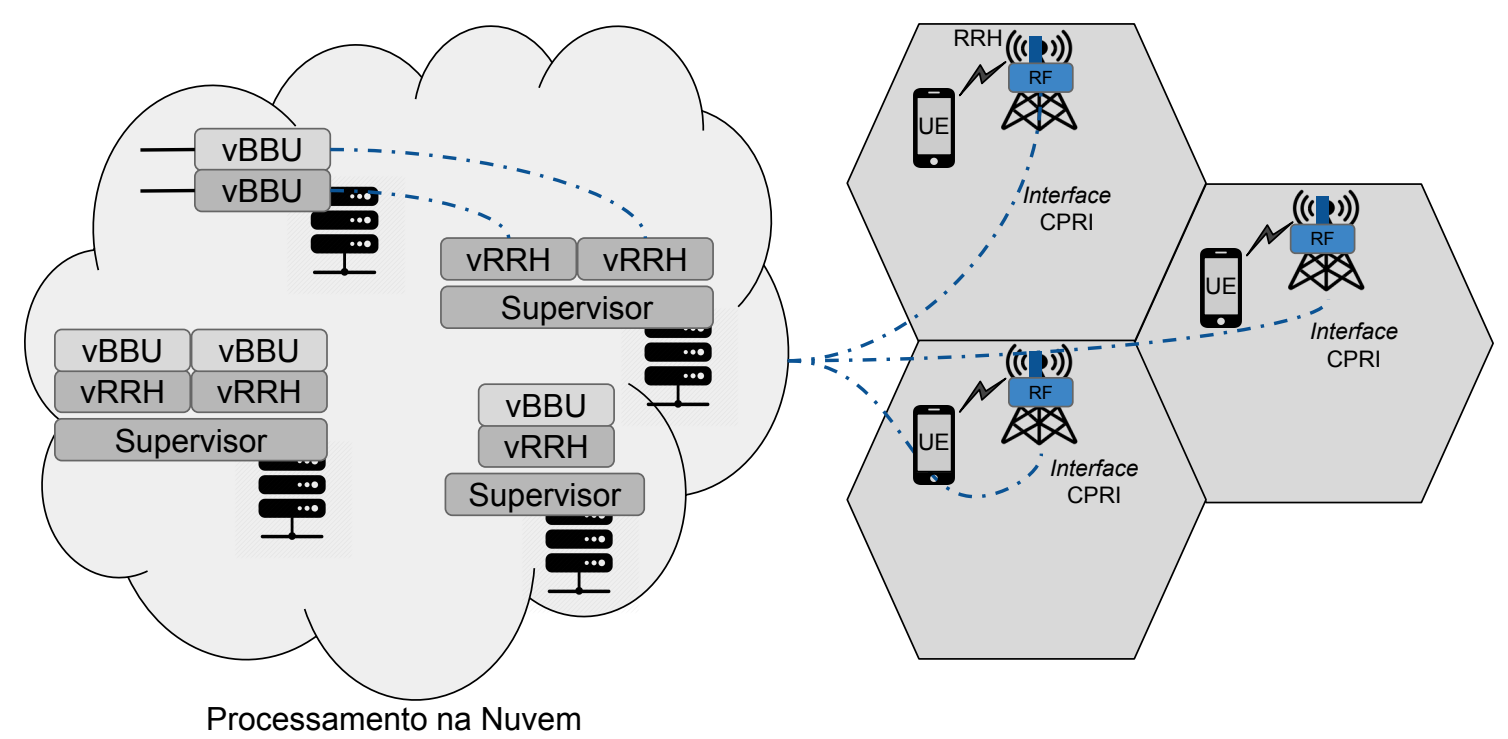

Figura 3.14. RAN virtualizada.

fatiamento propostas pela 3GPP ainda são tema de pesquisa [47] e desenvolvimento pela academia e indústria, pois requisitos de virtualização, processamento e funcionalidades ainda precisam ser investigados.

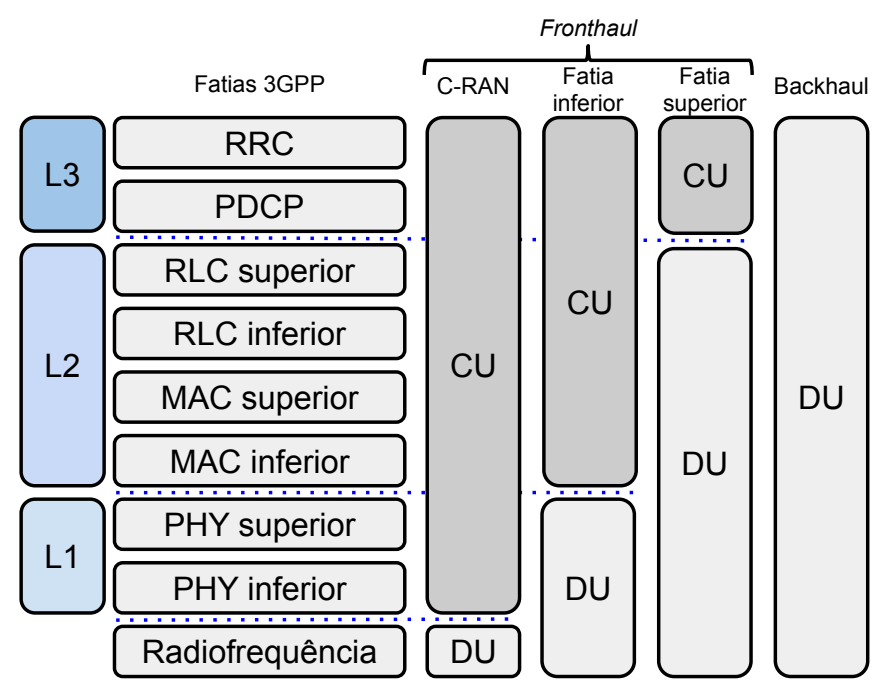

Figura 3.15. Divisão de funções entre unidade central e distribuída.

É importante ressaltar que essa nova arquitetura flexível da RAN composta de unidades distribuídas de dados (DU/gNB-DU) e controle (CU/gNB-CU) trouxe mudanças para a rede de transporte entre o acesso e o núcleo do sistema 5G. Atualmente, a rede de transporte está sendo reprojetada e desenvolvida considerando segmentos de fronthaul, midhaul e backhaul. O fronthaul é responsável pela comunicação entre a RRH/vRRH e o DU/gNB-DU. No segmento midhaul, ocorre a comunicação entre o DU/gNB-DU e 
CU/gNB-CU. Por fim, o backhaul realiza a comunicação entre o CU/gNB-CU e o novo núcleo do sistema 5G. Também são comuns abordagens que adotam a integração entre os segmentos de transporte, em uma configuração de crosshaul [46, 47], na qual o objetivo explorar o uso eficiente de recursos de transporte de alto custo. orquestração das cargas de trabalho de vRANs nessa nova arquitetura é tema de grande investigação atualmente.

\subsubsection{Demonstração de RAN}

\section{Objetivos}

Um objetivo da demonstração é apresentar de maneira prática as funcionalidades de uma RAN, utilizando software e hardware abertos. Outro objetivo é comentar brevemente os processos de instalação e configuração do software que implementa a RAN, deixando material disponível para replicação desta demonstração.

\section{Descrição}

Nesta demonstração, utilizamos uma rede de acesso baseada em tecnologia LTE de projetos de código aberto. Além da RAN, é apresentado também software capaz de emular o funcionamento de UEs. A demonstração é organizada em 3 experimentos: (1) UE e RAN em software, sem núcleo; (2) UE, RAN e núcleo EPC em software; e (3) UE em hardware (celular convencional), RAN em hardware (SDR - software-defined radio) e software e núcleo EPC em software. Todos os componentes são implementados utilizando contêineres Docker que podem ser hospedados em uma infraestrutura de nuvem. A Figura 3.16 apresenta os componentes de software e hardware que são utilizados na demonstração da RAN.

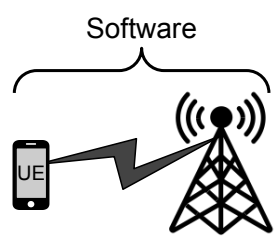

(1)

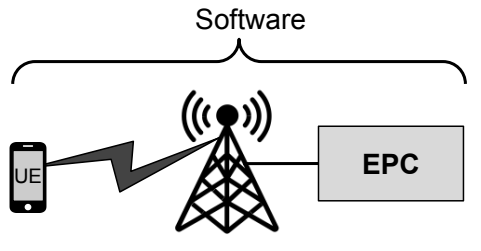

(2)

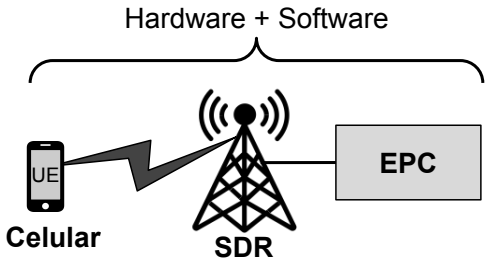

(3)

Figura 3.16. Demonstração de uma RAN softwarizada.

\section{Mais informações}

Durante o minicurso, são apresentados vídeos de demonstração dos experimentos. Além disso, estão disponíveis manuais com detalhes sobre como os experimentos podem ser replicados. Por fim, contêineres e qualquer código extra produzido pela equipe e que sejam necessários para replicar os experimentos estão também disponíveis publicamente.

Repositório deste minicurso: 


\subsection{Núcleo da rede}

Dentro do escopo de redes móveis, o núcleo pode ser caracterizado como o elemento de maior criticidade em um sistema 5G. O Lançamento 15 da 3GPP [6] estruturou o núcleo tendo como base um conjunto de componentes interconectados por uma camada de serviços. Cada componente possui uma responsabilidade específica, além de consumir e/ou fornecer serviços para os demais elementos do sistema 5G, através de APIs (Application Programming Interface) definidas pelo padrão. Essa estrutura, formada por componentes de software e suas interconexões via APIs, é ilustrada na Figura 3.17. O Lançamento 15 introduziu mudanças substanciais na maneira como as redes móveis são projetadas com o objetivo de fornecer suporte a uma ampla gama de serviços, cada um deles com requisitos de desempenho distintos [9].

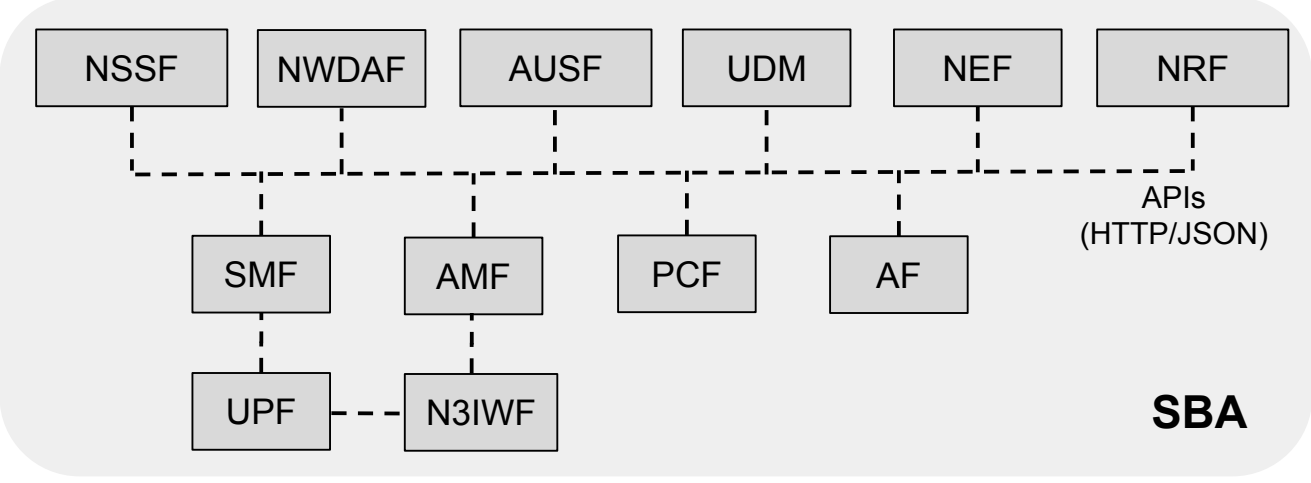

Figura 3.17. Principais componentes de software do núcleo 5G.

Dada a relevância do núcleo $5 \mathrm{G}$, cada um dos elementos que o compõem necessitam ser robustos, resilientes, ter alta disponibilidade e escalabilidade. Essas são características normalmente associadas ao conceito de computação em nuvem. No contexto do Lançamento 15 , cada um dos componentes que compõem o novo núcleo $5 \mathrm{G}$ podem ser decompostos em VNFs (Virtual Network Functions. Desta forma, cada VNF pode estar disponível sob demanda em uma infraestrutura na nuvem. A utilização baseada na decomposição de VNFs tornou-se possível porque os componentes não estão interconectados ponto-a-ponto através de interfaces físicas como em arquiteturas anteriores. Ao invés disso, cada um dos componentes do núcleo deve expor um conjunto de funcionalidades via software, através da arquitetura baseada em serviços (SBA) [48]. Nesse contexto, cada VNF oferece um ou mais serviços para outras VNFs. Pela nova definição da arquitetura SBA, a exposição de funções aplica-se apenas ao contexto de sinalização e não à transferência de dados do usuário.

Um dos métodos de comunicação que pode ser utilizado para uma arquitetura SBA tem como base REST (Representational State Transfer) sobre HTTP (HyperText Transfer Protocol). Esse método consiste em um conjunto de regras e diretrizes, amplamente utilizados na interconexão de sistemas distribuídos, que definem como as tecnologias de comunicação na Web acessam serviços através da utilização de APIs. Aparentemente, a expectativa por parte da $3 \mathrm{GPP}$ é tornar mais simples a tarefa de estender os recursos da rede. Outro aspecto a ser observado acerca do mecanismo de comunicação é que o 
mesmo deve ser visto como uma opção lógica, dado que a especificação dos componentes que implementam as VNFs pressupõe que esses estejam executando em um ambiente virtualizado [49]. Os componentes que constituem o núcleo $5 \mathrm{G}$ podem ser vistos como uma malha interconectada de serviços. Cada VNF de um componente desempenha responsabilidades especificas e se interconectam a outras VNFs produzindo e consumindo serviços. As principais características de cada um desses componentes são descritas nas subseções a seguir. Cabe destacar que descrevemos brevemente os principais componentes presentes no núcleo $5 \mathrm{G}$, sem o objetivo de listar todos os componentes e nem realizar uma apresentação exaustiva. A lista completa de componentes e sua descrição detalhada exige centenas (ou até milhares) de páginas do padrão ou um livro completo a respeito [50].

\subsubsection{Principais componentes}

\section{Access and Mobility Management Function (AMF)}

A mobilidade pode ser considerada a essência de um sistema 5G. O gerenciamento de mobilidade tem início no momento em que se estabelece uma nova conexão entre um UE e o núcleo da rede. Essa ação desencadeia uma série de procedimentos para identificar o UE, provendo uma estrutura de segurança, com o objetivo de fornecer um canal para o transporte de mensagens. O principal objetivo do componente AMF é garantir que o processo de comunicação se realize de forma coesa e transparente, considerando como fator chave a mobilidade do usuário. Através das funções implementadas no AMF a rede pode, por exemplo, alcançar um determinado usuário para notificá-lo sobre eventuais mensagens ou chamadas recebidas. Além disso, o componente AMF pode permitir, por exemplo, que um determinado UE dê início a um processo de comunicação com outros UEs também conectados na RAN ou que tenha acesso à Internet. Outra funcionalidade importante do AMF é garantir a conectividade e que as eventuais sessões existentes possam ser mantidas à medida que o UE se move entre diferentes pontos de acesso.

Em redes 5G, existe a necessidade de fornecer um suporte flexível para uma ampla gama de novos usuários [9]. Muitos desses usuários possuem necessidades específicas no que diz respeito a mobilidade. Por exemplo, um determinado UE utilizado em uma fábrica normalmente não se move, enquanto o UE em veículo autônomo ou controlado remotamente pode se apresentar alta mobilidade. Para melhor suportar essas diferentes necessidades, a especificação no Lançamento 15 [6] dividiu os procedimentos de mobilidade em três categorias para o componente AMF:

- Procedimentos Comuns podem ser caracterizados como um conjunto de etapas que serão executadas quando qualquer UE solicitar uma conexão com o núcleo. Dentre essas etapas, se destacam o processo de segurança, composta de autenticação primária, gerenciamento das chaves de acesso, identificação e configuração básica do UE.

- Procedimentos Específicos têm a função de gerenciar o registro e a atualização periódica da mobilidade de um determinado UE no AMF. Além disso, esse procedimento controla o encerramento do registro de um UE, dado um escopo de diferentes tecnologias de acesso. 
- Procedimentos de Gerenciamento de Conexão são utilizados para estabelecer um processo de comunicação segura entre um determinado UE e o núcleo. Além disso, esse procedimento é utilizado quando um determinado UE necessita executar um processo de reserva de recursos da rede para o envio de dados.

Cada uma dessas categorias de procedimentos tem como objetivo prover funcionalidades que permitam UEs estabelecerem conexões com o núcleo da rede, utilizando os serviços associados à mobilidade.

\section{Session Management Function (SMF)}

O componente SMF é responsável por gerenciar as sessões dos UEs, isto é, as sessões que representam os usuários conectados. As principais responsabilidades do SMF estão associadas às atividades de estabelecer, modificar e liberar as sessões individuais dos UEs, além de alocar os endereços IPs para cada UE conectado. Entretanto, a comunicação entre UEs e SMF é realizada de forma indireta através do componente AMF. Cabe ao AMF encaminhar as mensagens associadas à sessão de determinado UE e às funções do componente SMF.

As funções internas do componente SMF interagem com as demais VNFs dos outros componentes através do modelo produtor/consumidor, definida de acordo com a arquitetura SBA [48]. Por exemplo, o SMF desempenha a responsabilidade de controlar diferentes funções associadas ao componente UPF. Esse controle inclui a capacidade do SMF de configurar a direção do tráfego de dados associado a um UPF, para uma determinada sessão do UE. Além disso, o SMF deve executar ações de monitoramento e controle no UPF. O componente SMF também interage com funções associadas ao PCF, com o objetivo de executar a política das sessões dos UEs conectados. Essa ação de execução pode ser descrita como uma das principais tarefas associadas a um sistema 5G. Para ilustrar, é essa ação que determina as diretrizes para prover conectividade de dados entre um UE e a rede de dados (DN - Data Network).

\section{User Plane Function (UPF)}

O Lançamento 15 da 3GPP [6] caracteriza o componente UPF como uma função fundamental dentro da nova arquitetura SBA. O UPF pode ser visto como parte do processo de separação entre Plano de Controle e Plano de Dados, inicialmente, introduzido no Lançamento 14 [51] com CUPS. O desacoplamento entre dados e controle, possibilita a arquitetura SBA descentralizar ainda mais seus componentes. Por exemplo, é possível direcionar atividades como processamento de pacotes para ficarem posicionados mais próximos da borda da rede, aumentando a QoS para o usuário e reduzindo o tráfego de rede.

As funcionalidades implementadas no componente UPF são controladas pelo SMF. A principal função do UPF está associada ao encaminhamento e ao processamento de dados dos UEs. Esse componente é ainda responsável por gerar notificações associadas ao tráfego de dados e pelo processo de inspeção de pacotes. O UPF funciona também como ponto estável de ancoragem entre o núcleo e as eventuais redes externas. O UPF possibilita que a comunicação aconteça de forma transparente, ocultando aspectos de complexidade associados à mobilidade. Pacotes IP destinados a um determinado UE são 
encaminhados (da Internet) para o respectivo UPF, que esteja atendendo esse UE, mesmo quando o UE está em mobilidade. De uma forma geral, o componente UPF é responsável por:

- Desempenhar o papel de ancoragem entre o núcleo e as redes externas;

- Atuar como um ponto de acesso externo para PDUs (Protocol Data Unit), interconectando diferentes redes de dados;

- Realizar o roteamento/encaminhamento de pacotes, além de inspecionar os pacotes com o objetivo de detectar características de aplicações;

- Aplicar as definições associadas à gestão do plano de dados do usuário, bem como prover informações do tráfego de dados.

\section{Authentication Server Function (AUSF)}

O AUSF é responsável pelo serviço que realiza autenticação dos UEs através das credenciais de acesso fornecidas pelo UDM. Além disso, o AUSF provê serviços associados a criptografia para possibilitar o tráfego de informações seguras e permitir a execução de processos de atualização de informações de deslocamento (roaming), bem como demais parâmetros associados ao UE.

De uma forma geral, os serviços providos pelo componente AUSF são consumidos pelas funções do AMF, as quais solicitam recursos associados ao processo de autenticação. As solicitações das funções do componente AMF são processadas internamente pelo AUSF e, posteriormente, delegadas a serviços providos pelo componente UDM, para execução de procedimentos de registro no repositório de dados.

\section{Unified Data Management (UDM)}

O UDM é o componente responsável por gerenciar os dados dos usuários da rede em um único elemento centralizado. O UDM é equivalente ao HSS do núcleo EPC/4G. Através do UDM, diversas VNFs da arquitetura SBA conseguem executar diferentes ações, tais como: registro e autenticação de UEs, identificação de usuários, aplicação de políticas de acesso e autorização, dentre outras. O componente UDM interage diretamente com o AMF que encaminha as solicitações dos demais componentes. Além disso, em cenários onde existem mais de uma instância do componente AMF na rede, o UDM deve controlar quais instâncias serão as responsáveis por atender um UE específico [52]. Dentre as funcionalidades do UDM, se destacam [53]:

- Geração de credenciais de autenticação 3GPP AKA (Authentication and Key Agreement);

- Tratamento de identificação do usuário;

- Suporte à ocultação do identificador de assinatura protegido por privacidade;

- Autorização de acesso com base em dados de assinatura (por exemplo, restrições associadas à mobilidade); 
- Gerenciamento de assinaturas;

- Gerenciamento de SMS.

O componente UDM funciona como a parte dianteira (front-end) para os dados de assinatura do usuário que são armazenados no UDR (Unified Data Repository). O UDM usa esses dados de assinatura para executar a lógica de diversas aplicações, como autorização de acesso, gerenciamento de registro e acessibilidade para finalização de eventos. O UDR é um banco de dados onde vários tipos de dados são armazenados e cujo acesso é oferecido como serviço para outros componentes como UDM, PCF e NEF. Existe ainda um componente de armazenamento opcional chamado UDSF (Unstructured data storage function), o qual permite que outros componentes (ou funções) armazenem dados de contexto dinâmico fora da própria função (ou componente). No contexto $3 \mathrm{GPP}$, dados não estruturados se referem àqueles cuja estrutura não está definida nas especificações, permitindo que cada fornecedor que use um UDSF e escolha sua própria estrutura específica para o armazenamento. Não há exigência de qualquer compatibilidade de acesso ou armazenamento de dados em UDSF de diferentes fornecedores.

\section{Policy Control Function (PCF)}

Esse componente desempenha a mesma função que o PCRF do EPC no sistema 4G. O PCF é o responsável por controlar o comportamento da rede, aplicando regras de segurança e controle, relacionadas ao gerenciamento das sessões, sobretudo àquelas funcionalidades associadas à mobilidade do usuário. Ele interage diretamente com o AMF, visando prover uma política de acesso e de mobilidade que pode incluir dentre outras coisas, o gerenciamento de restrições de acesso a serviços de uma determinada área, bem como a gestão de questões associadas à prioridade de acesso ao meio de determinados UEs em detrimento a outros (RFSP - Radio Frequency Selection Priority).

No contexto do gerenciamento de sessão, o PCF pode interagir com as funções de aplicação e com o SMF. O principal objetivo é prover métricas associadas à qualidade do serviço, bem como informações referentes ao fluxo de dados, as quais são obtidas pelo monitoramento regular de eventos associados à sessão de PDU. PCF também provê informações de políticas de segurança dos UEs. Essas políticas podem estar associadas a recursos de seleção de rede e regras para a seleção de fatiamento de recursos. O PCF pode ser acionado, por exemplo, para fornecer informações quando um determinado dispositivo realizar uma seleção de acesso (UE access selection) ou quando ocorrer o estabelecimento de uma sessão PDU [50]. A interação entre o PCF e as demais funções de aplicação, são implementadas através da exposição de seis serviços, a saber:

- PCF-AM-PolicyControl - provê informações relacionados a políticas de controle de acesso, seleção de rede, gerenciamento de mobilidade e diretrizes que podem ser aplicadas na seleção de rotas entre UEs e AMFs;

- PCF-PolicyAuthorization - fornece autorização e provê políticas de controle de acesso a uma requisição de um elemento AF, relacionado à sessão PDU a qual o AF está vinculado; 
- PCF-SM-PolicyControl - fornece a um componente SMF, diretivas de acesso relacionadas à sessão PDU a qual o componente está vinculado;

- PCF-BDT-PolicyControl - fornece ao elemento NEF um conjunto de diretrizes que podem ser utilizadas por aplicações para realizar a transferência de dados em segundo plano;

- PCF-UE-PolicyControl - fornece diretrizes de controle que podem ser utilizadas no gerenciamento do processo de comunicação entre os UEs e demais funções de rede;

- PCF-Event-Exposure - possibilita que as demais funções de rede se inscrevam para serem notificadas quando um determinado evento vier a acontecer.

As decisões sobra a aplicação das políticas de monitoramento e controle realizadas pelo PCF são embasadas, em parte, por informações analíticas fornecidas por outras funções de rede, como a NWADF. O PCF também é um componente de fundamental importância em um cenário onde um AF necessite realizar uma atividade específica, por exemplo, a transferência de dados em segundo plano. Nesse caso, o AF pode entrar em contato com o PCF com o objetivo de inferir qual o melhor intervalo de tempo para a execução da atividade. Isso possibilita ao operador do sistema disponibilizar informações aos fornecedores de aplicativos sobre o momento mais adequado para se realizar a transferência de dados em segundo plano.

\section{Network Repository Function (NRF)}

O componente NRF é o repositório onde todas as funções disponíveis para uma determinada rede são listadas. O objetivo desse componente é permitir que outras VNFs consigam encontrar a função adequada para atender seus requisitos. O NRF tem a responsabilidade de selecionar o componente provedor de serviços mais adequado mediante critérios de desempenho fornecidos. Desta forma, o componente NRF é atualizado sempre que uma nova instância de VNF for implantada ou modificada. Além disso, o NRF detém informações sobre as demais VNFs, tais como tipo, capacidade, endereço, dentre outras.

Dentro do escopo SBA, o componente NRF desempenha papel fundamental para o funcionamento das demais VNFs. Esse componente oferece um mecanismo central que é capaz de automatizar todo o processo de configuração necessário para que as demais VNFs consigam descobrir e se conectar a outros serviços especializados.

\subsubsection{Outros componentes importantes}

\section{Network Slice Selection Function (NSSF)}

No contexto de redes 5G, o fatiamento de rede (Network Slicing) pode ser definido como a possibilidade do operador do sistema alocar um conjunto de recursos (em geral, virtualizados), com o objetivo de atender aos requisitos de determinados serviços ou aplicações [54]. O objetivo é fornecer suporte a um vasto conjunto de serviços, cada um deles com demandas específicas de desempenho [9]. As fatias de recursos virtuais são 
na verdade instâncias lógicas de recursos de rede, os quais são necessários para atender a uma demanda específica. Uma fatia pode incluir recursos do núcleo e da RAN, e até extrapolar para redes de transporte entre diferentes núcleos e RANs, sendo considerada de serviço de rede do tipo ponta-a-ponta.

A arquitetura do núcleo 5G define o componente NSSF como sendo o responsável por gerenciar as instâncias de fatias de rede disponíveis. Ele é o responsável por selecionar as instâncias de fatias de rede, juntamente com o conjunto de AMFs disponíveis para um determinado UE. O AMF pode ser um componente dedicado a uma fatia específica ou atender a um conjunto de instâncias de fatias de rede. A função do NSSF é auxiliar o AMF na escolha das fatias de rede disponíveis, redirecionando do tráfego entre as fatias de rede controladas. O NSSF pode ser visto como um orquestrador, capaz de influenciar a maneira como o tráfego de rede é roteado. Ele produz dois serviços, um serviço seleção que produz informações acerca da fatia de rede selecionada e um outro serviço de disponibilidade que produz informações acerca das fatias de recursos disponíveis.

\section{Network Exposure Function (NEF)}

O componente NEF é responsável por expor alguns eventos internos, relacionados a UEs e a arquitetura SBA. A exposição desses eventos visa atender a demanda de aplicações específicas e VNFs de outros componentes. Por exemplo, essas demandas necessitam ter acesso à localização de um determinado UE ou serem notificadas sobre a interrupção de conectividade de um determinado equipamento. Além disso, essas informações podem permitir o componente AMF ajustar o sistema de acordo com o comportamento de um grupo de usuários.

A possibilidade de expor eventos internos através de uma interface de acesso NEF abre novas oportunidades de negócio para provedores de serviços, permitindo que em alguns casos, serviços mais avançados possam ser oferecidos por terceiros. Por exemplo, uma aplicação pode utilizar os serviços expostos pelo componente NEF para saber se um determinado UE está ou não acessível, além de determinar a localização geográfica desse UE ou saber se o mesmo está em movimento. O componente NEF antede às solicitações das diferentes VNFs através de interações regulares entre os componentes UDM e AMF.

\section{Network Data Analytics Function (NWDAF)}

O NWDAF é um componente opcional na arquitetura do núcleo e é o responsável por coletar diversos tipos de informações, oriundas da rede e de seus respectivos usuários. Essas informações são posteriormente organizadas e analisadas com o objetivo de prover os resultados inferidos para outras funções de rede. A descrição deste componente foi realizada de forma superficial no Lançamento 15 [6], sendo que sua especificação detalhada está prevista para o Lançamento 16.

Os dados coletados pelo NWDAF são oriundos de várias outras funções de rede que compõe o núcleo. A coleta dos dados é realizada através da camada de serviços que interliga os componentes do núcleo via serviço de escrita. Esse serviço pode ser acionado pelos eventos internos disparados por cada componente. O NWDAF também coleta informações sobre o funcionamento do sistema, bem como dados de registro de informações no componente UDR. 
Segundo a especificação, os serviços fornecidos pelo NWDAF podem ser consumidos por qualquer outro componente do núcleo. O acesso externo também é possível através da utilização do mecanismo do componente NEF. As análises realizadas pelo NWDAF nos dados coletados ao longo do tempo podem ser utilizadas como um recurso histórico/estatístico visando prever valores futuros. Os dados analíticos produzidos pelo NWDAF podem também ser utilizados para aplicar determinadas ações no contexto da rede.

\section{Application Function (AF)}

AF é um componente genérico que representa uma possível aplicação, interna ou externa à rede da operadora, o qual interage com a arquitetura SBA. O processo de interação de AFs com SBA pode influenciar alguns aspectos de todo o sistema. Por exemplo, um AF pode interagir com o componente PCF através de serviços expostos pelo componente NEF, influenciando aspectos de QoS e, consequentemente, as políticas de cobrança/tarifação.

Um fator importante que deve ser avaliado pelo operador do sistema é o grau de confiança que um AF pode ter para interagir diretamente com determinadas VNFs. Por exemplo, um AF com maior confiabilidade poderia acessar diretamente VNFs de todos os componentes da arquitetura SBA, enquanto um AF menos confiável deveria primeiramente interagir com o componente NEF antes de ter acesso a funções mais sensíveis da rede.

\section{Non-3GPP InterWorking Function (N3IWF)}

O componente N3IWF é usado para integrar acessos não-3GPP com o núcleo 5G. O WiFi (IEEE 802.11) e DOCSIS (Data Over Cable Service Interface Specification) são exemplos de tecnologias de acesso não-3GPP previstas para integração pelo padrão. Conforme descrito anteriormente, o acesso 3GPP convencional utiliza uma BS, por exemplo, eNB (4G) ou gNB (5G). No entanto, o acesso não-3GPP se inicia em um dispositivo diferente, por exemplo, um ponto de acesso WiFi ou um modem HFC (Hybrid fiber-coaxial). Esse dispositivo usa o componente N3IWF para ter acesso à rede 3GPP, inclusive aos demais componentes do núcleo $5 \mathrm{G}$.

Todo o tráfego a partir do componente N3IWF é transmitido através de canais seguros e é isolado de todos os demais tráfegos 3GPP. O isolamento é mantido não apenas para tráfego de dados (como é comum para comunicações 3GPP), mas também para tráfego de controle, inclusive o que ocorre antes do processo de autenticação. Mais detalhes do componente N3IWF, com sua utilização e a comunicação com outros componentes da arquitetura, são descritos na Subseção 3.6.1.

\subsubsection{Demonstração de núcleo 5G}

\section{Objetivos}

O objetivo da demonstração é apresentar de maneira prática as principais funcionalidades do núcleo $5 \mathrm{G}$ baseado em SBA. Além disso, comentaremos os processos de instalação e configuração do software que implanta o núcleo $5 \mathrm{G}$, deixando disponível material para replicação desta demonstração. Pretendemos também apresentar alguns co- 
mentários sobre o desenvolvimento de um núcleo $5 \mathrm{G}$, mostrando como a estrutura inicial do código pode ser criada a partir das especificações da $3 \mathrm{GPP}$.

\section{Descrição}

Nesta demonstração, utilizamos o núcleo $5 \mathrm{G}$ baseado na arquitetura SBA de código aberto. Além do núcleo, é apresentado também software capaz de emular o funcionamento de RAN e UEs. A demonstração é organizada em 2 experimentos: (1) UEs, RAN e núcleo em software e (2) UE em hardware (celular convencional), UEs emulados por software, RAN em hardware (SDR), RAN emulada por software, bem como o núcleo 5G em software. Todos os componentes são implementados utilizando contêineres Docker que podem ser hospedados em uma infraestrutura de nuvem. A Figura 3.18 apresenta os componentes de software e hardware que são utilizados na demonstração do núcleo $5 \mathrm{G}$.

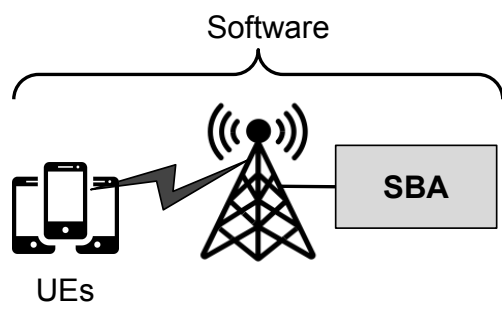

(1)

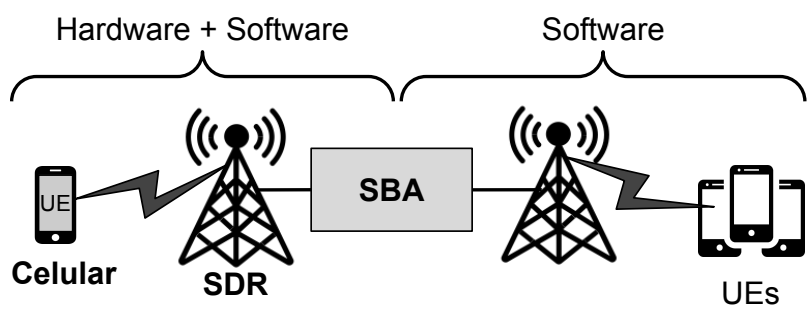

(2)

Figura 3.18. Demonstração do núcleo 5G.

\section{Mais informações}

Durante o minicurso, são apresentados vídeos de demonstração dos experimentos. Além disso, estão disponíveis manuais com detalhes sobre como os experimentos podem ser replicados. Por fim, contêineres e qualquer código extra produzido pela equipe e que sejam necessários para replicar os experimentos estão também disponíveis publicamente.

Repositório deste minicurso:

https://github.com/LABORA-INF-UFG/SBRC2020-Minicurso3.

\subsection{Redes $5 \mathrm{G}$ integradas a redes de acesso sem fio heterogêneas}

Embora as redes $5 \mathrm{G}$ tenham sido projetadas para atender uma ampla variedade de serviços, oferecendo uma vasta gama de recursos, a 3GPP previu no Lançamento 15 a integração e suporte a outras tecnologias de acesso sem fio não-3GPP, com atenção especial para WiFi (IEEE 802.11). Como já foi discutido em outros trabalhos [55], [23], a coexistência de diferentes tecnologias de acesso promovem ganhos significativos em relação a desempenho e custo da comunicação de dispositivos de IoT. Além disso, existe uma imensa quantidade de dispositivos que possuem interfaces sem fio não-3GPP e que estarão em uso durante alguns anos. A integração de múltiplas tecnologias de acesso sem fio em um único núcleo tem o potencial de beneficiar tanto usuários, quanto administradores de infraestrutura de comunicação pública e privada. 
O Lançamento 15 [56] já define como uma tecnologia de rede sem fio não-3GPP pode ser usada como acesso e integrada a um núcleo 5G. No entanto, esse lançamento visa apenas redes locais sem fio (WLANs - Wireless Local Area Networks), i.e., redes WiFi, considerando o acesso não-confiável (untrusted). O acesso confiável (trusted) será introduzido no Lançamento 16 [57]. Nesse lançamento, está sendo dada atenção também às tecnologias de acesso a cabo, em especial HFC. Embora os padrões 3GPP não descrevam de forma específica como integrar outras tecnologias de comunicação sem fio usadas em IoT, como LoRa ou ZigBee, o arcabouço utilizado permite extensões que podem ser exploradas para esse fim [58, 59]. A seguir, apresentamos mais detalhes sobre o Lançamento 15 e também sobre a tecnologia LoRa/LoRaWAN, que usaremos como ilustração da integração entre o núcleo $5 \mathrm{G}$ e uma tecnologia de acesso sem fio não-3GPP, ao fim desta seção.

\subsubsection{Redes de acesso não-3GPP}

A arquitetura do núcleo $5 \mathrm{G}$ prevê, desde seu projeto, a possibilidade de integrar tecnologias de acesso não-3GPP, tendo como premissa que as interfaces de comunicação oferecem conectividade IP, i.e., uma pilha IP tradicional. Embora essa premissa seja atendida por tecnologias como WiFi e HFC, várias tecnologias IoT, como LoRa, ZigBee, nRF24 e outras assumem que existirá um gateway para prover a conectividade IP para os dispositivos IoT. Portanto, vamos assumir a partir deste ponto no texto que um equipamento com pilha IP tradicional, i.e., um dispositivo ou um gateway, estará disponível para estabelecer a integração. É importante destacar, como descrito em [59], que existem diferentes maneiras de realizar a integração de dispositivos que dependem de um gateway com pilha IP tradicional.

O núcleo EPC da 4G também possui suporte para redes de acesso não-3GPP, porém, usando uma abordando mais complexa. Além de definir entre acesso confiável e não-confiável, é preciso escolher entre mobilidade baseada em rede e mobilidade baseada em hospedeiro. Dada o foco do minicurso, não serão apresentadas mais informações sobre a abordagem usada no núcleo EPC, mas uma descrição completa pode ser encontrada em [60]. Para o núcleo SBA da 5G, foram definidas menos opções, basicamente, acesso não-3GPP não-confiável (Lançamento 15, congelado em março de 2019 e concluído em junho de 2019) e confiável (Lançamento 16, com previsão de congelamento para março de 2020 e conclusão junho de 2020). Nesse contexto, o termo não-confiável significa que o operador da rede $3 \mathrm{GPP}$ não confia na segurança oferecida pela rede de acesso não-3GPP e, portanto, precisa tomar ações que garantam o transporte adequado do tráfego dessa rede de acesso. Isso significa que o tráfego não-3GPP deve ser isolado dos demais, inclusive no núcleo 5G, que é adequado para aplicações e serviços IoT. O acesso confiável não há prevê integração de outras tecnologias de comunicação sem fio usadas em IoT, como LoRa ou ZigBee.

Para dar suporte a redes de acesso não-3GPP não-confiável, o principal componente introduzido pelo Lançamento 15 da 3GPP foi o N3IWF (Non-3GPP Interworking Function), que é responsável por reencaminhar sinalização e dados entre o núcleo $5 \mathrm{G}$ e a rede de acesso não-3GPP, como descrito na Subseção 3.5. A Figura 3.19 ilustra a integração de duas redes de acesso não-3GPP a um núcleo $5 \mathrm{G}$, mostrando os principais componentes envolvidos e suas interfaces de comunicação. O componente N3IWF seleci- 
ona o AMF para servir o dispositivo (ou gateway) IoT, a qual será responsável por cuidar da (eventual) mobilidade do dispositivo assim como intermediar toda a sinalização com outras funções do núcleo 5G. Para se comunicar efetivamente, um dispositivo precisa de sessões PDU, que são estabelecidas, modificadas e liberadas sobre o controle do componente SMF. Esse componente funciona como um plano de controle que opera sobre plano de dados implementado através do UPF.

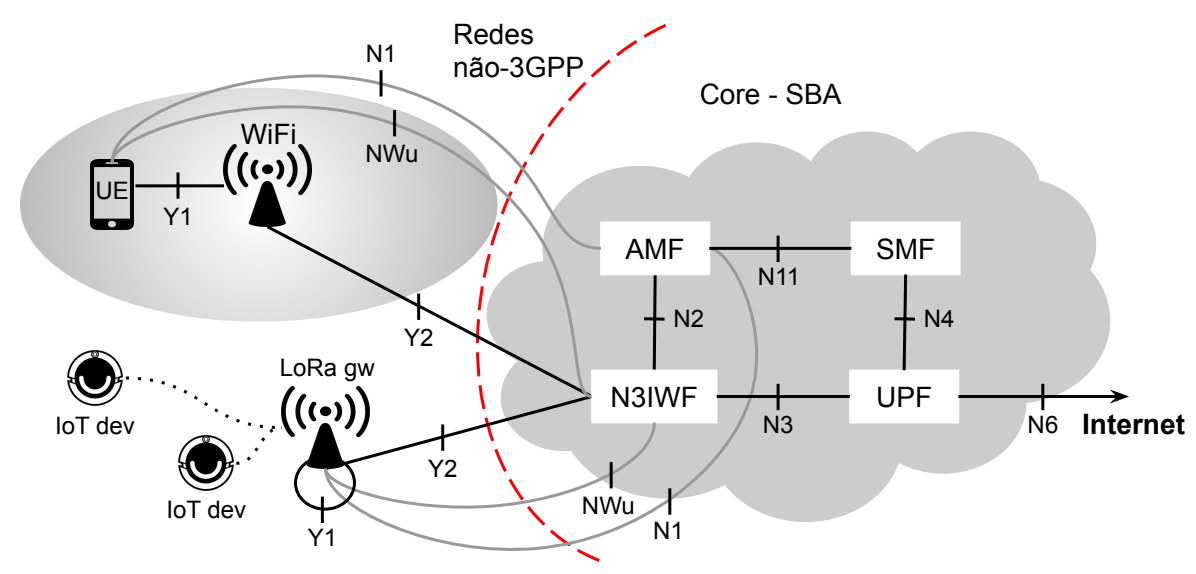

Figura 3.19. Integração entre redes de acesso não-3GPP não-confiável ao núcleo SBA da 5G.

No núcleo SBA da 5G, o componente AUSF permite que um dispositivo se autentique para ter acesso à rede e seus serviços, podendo usar tanto uma interface sem fio 3GPP (e.g., NR) quanto uma interface não-3GPP (e.g., WiFi). Os dispositivos não$3 \mathrm{GPP}$ podem autenticar com o núcleo SBA através de um esquema baseado em certificados, usando EAP-TLS (Extensible Authentication Protocol - Transport Layer Security) ou EAP-TTLS (EAP - Tunneled TLS), além do procedimento tradicional com credenciais baseadas em SIM (Subscriber Identification Module). A Figura 3.20 ilustra as conexões estabelecidas para fornecer a integração entre as redes de acesso não-3GPP não-confiável e o núcleo SBA da $5 \mathrm{G}$.

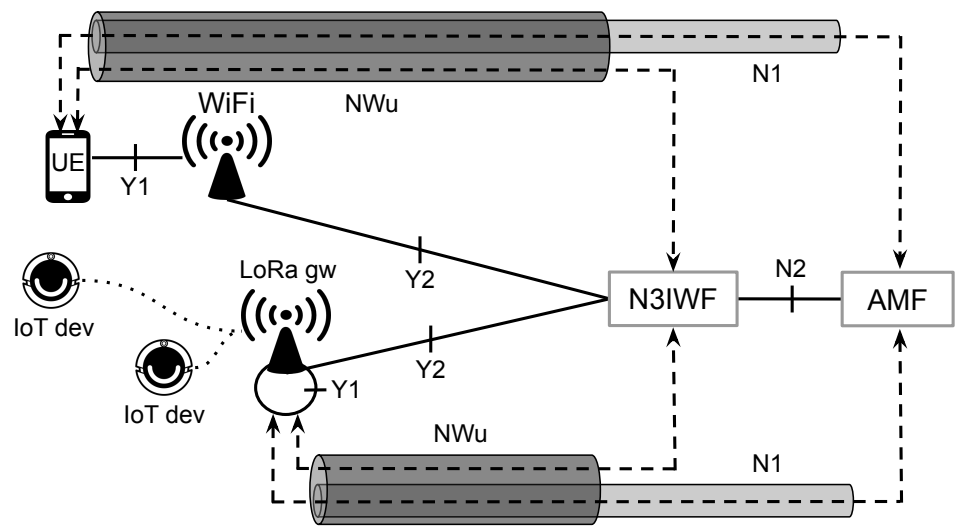

Figura 3.20. Conexões para a integração de redes de acesso não-3GPP não-confiável com o núcleo SBA da $5 G$. 
A conexão Y1 não é especificada pela 3GPP, mas consiste em estabelecer a comunicação do dispositivo com sua rede de acesso, por exemplo, através de um ponto de acesso WiFi ou um gateway LoRa. É assumido que existe algum processo de autorização através da conexão Y1, que permite o dispositivo ter acesso à rede e obter um endereço IP. No entanto, várias tecnologias, como LoRa, não atribuem IP diretamente para os dispositivos e, portanto, parte de conexão Y1 precisa ser implementada no próprio gateway da tecnologia. A conexão Y2 também não é especificada pela $3 \mathrm{GPP}$, mas deve oferecer a comunicação entre a rede de acesso e o componente N3IWF do núcleo SBA. Essa conexão pode ser estabelecida praticamente de qualquer forma, inclusive através da Internet pública, i.e., potencialmente com múltiplos equipamentos e tecnologias intermediárias.

O padrão 3GPP especifica que entre o dispositivo (ou gateway) e o componente N3IWF deve ser estabelecido um túnel IPSec criptografado, chamado de NWu, para envio de tráfego de dados e de sinalização. o componente N3IWF seleciona o AMF para servir o dispositivo, sendo estabelecida a interface N2 entre as duas funções. Após estabelecimento da NWu e da N2, o padrão 3GPP especifica que é possível estabelecer a interface N1, entre dispositivo (ou gateway) e o componente AMF, para transportar sinalização NAS (Non-Access Stratum). Essa abordagem difere da utilizada no núcleo EPC da 4G, no qual a sinalização NAS se aplica apenas a redes de acesso 3GPP. Na SBA do núcleo $5 \mathrm{G}$, dispositivos se conectando através de redes de acesso não-3GPP são gerenciados de maneira similar a dispositivos se conectando através de redes de acesso 3GPP.

\subsubsection{LoRa}

A tecnologia LoRa, desenvolvida pela Semtech Corporation [61], permite comunicação a longas distâncias utilizando o conceito de espalhamento espectral (Spread Spectrum) de frequências de rádio. Essa tecnologia apresenta os seguintes parâmetros de configuração que influenciam diretamente no desempenho da comunicação:

- Fator de Espalhamento (SF - Spreading Factor) com valores de 7, 8, 9 ou 10. Quanto maior o SF, mais informações são transmitidas por símbolo, gerando um ganho na transmissão;

- Largura de Banda (BW - Bandwidth) de $125 \mathrm{kHz}, 250 \mathrm{kHz}$ ou $500 \mathrm{kHz}$ para um dado SF. Uma largura de banda mais estreita, aumenta a sensibilidade de recepção e incrementa o tempo de transmissão de um pacote;

- Taxa de Correção de Erro (CR - Code Rate ) é responsável pela detecção e correção de erros.

Essas configurações determinam a taxa de bits transmitida, o tamanho máximo dos dados transmitidos e o tempo de duração da transmissão de um pacote no espectro de RF. Desta forma, essas configurações também influenciam o tamanho das mensagens, o seu alcance e o consumo de energia do dispositivo IoT.

Segundo [62] e [63], LoRa é resistente a interferência, devido à sua ampla gama de SFs, que podem ser empregadas em ambientes urbanos, rurais e até mesmo industriais. Além disso, essa tecnologia oferece cerca de quatro vezes mais alcance de cobertura, se 
comparada com outras tecnologias de rádio, devido à sua natureza robusta e capacidade de atuar com sinais de rádio de baixa intensidade. Sua capacidade de realizar múltiplas transmissões no mesmo canal de RF, com a utilização de diferentes SFs diminui a probabilidade de colisões, aumentando a taxa efetiva de transmissão de dados, além de permitir discriminar entre erros de tempo e frequência. Desta forma, LoRa é considerada uma das tecnologias mais promissoras para a camada física de redes de sensores e, consequentemente, para a IoT [64]. Entretanto, para se ter uma aplicação efetiva de sensores e IoT é necessário ter uma rede, como LoRaWAN, que é descrita a seguir.

\subsubsection{Rede LoRaWAN}

Rede LoRaWAN é o nome dado as redes LPWAN (Low Power Wide Area Network) para IoT que utilizam como meio físico a tecnologia LoRa e implementam uma arquitetura baseada no protocolo de controle de acesso ao meio (MAC - Media Access Control) LoRaWAN. Na Figura 3.21, podemos observar a camada MAC, com suas subcamadas, enquanto a camada física LoRa habilita o enlace de comunicação de longo alcance. $\mathrm{O}$ protocolo da camada MAC e a arquitetura de rede têm grande influência na determinação da vida útil da bateria de um sensor, na capacidade da rede, na qualidade do serviço, na segurança e na variedade de aplicações IoT atendidas.

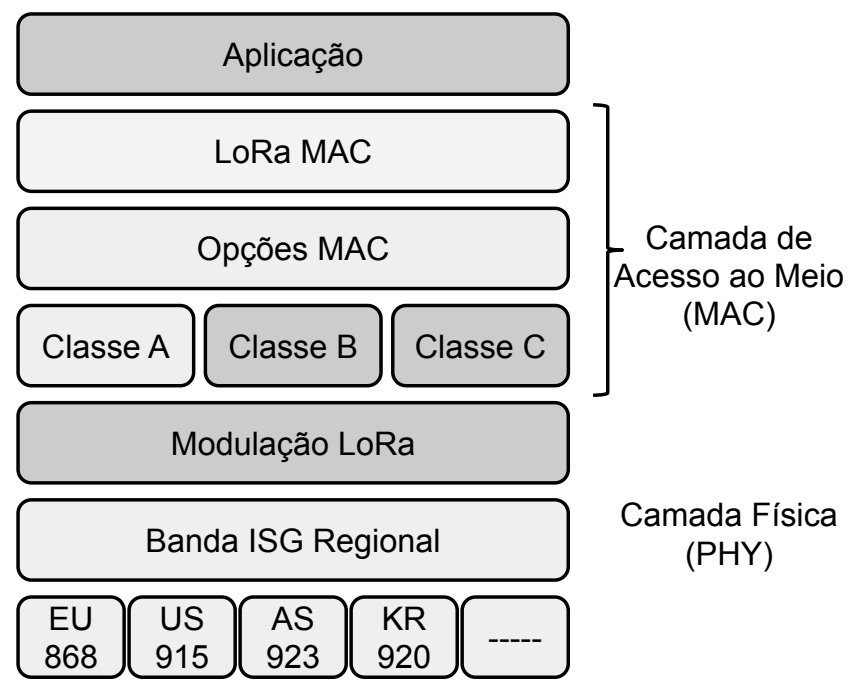

Figura 3.21. Camadas da arquitetura de rede LoRaWAN.

O protocolo LoRaWAN é baseado em padrões abertos e de baixo custo. Esse protocolo foi projetado desde o início para implementar plataformas para a IoT. Desta forma, o escopo de aplicação IoT suportadas é muito abrangente, tornando essa tecnologia muito atraente para ser conectada a sistemas $5 \mathrm{G}$ e criar uma rede IoT com grande área de cobertura. Entre as possíveis aplicações, encontram-se redes inteligentes para energia elétrica, rede de sensores de diversos tipos, agricultura de precisão, dentre outras.

A Figura 3.22 ilustra a topologia de referência do protocolo LoRaWAN. Uma característica proeminente dessa tecnologia é o baixo consumo, devido à topologia estrela que não necessita de roteamento entre nós. O elemento central é o gateway LoRaWAN 
que pode ser conectado ao sistema $5 \mathrm{G}$ em um acesso não-3GPP não-confiável. Esses gateways, também conhecidos como concentradores, possuem modelos que podem atender a necessidades específicas, mais simples e baratos para ambientes fechados, em contraposição aos modelos industriais com proteção contra intempéries e aplicações externas. $\mathrm{Na}$ comunicação entre gateway e dispositivo, são previstos dois tipos de troca de mensagens: mensagens sem confirmação (Unconfirmed Data Message), semelhantes às mensagens UDP (User Datagram Protocol), e com confirmação (Confirmed Data Message), semelhantes ao TCP (Transmission Control Protocol). Outra característica importante da rede LoRaWAN é a existência de 3 classes de dispositivos que se comunicam com os gateways, os quais são descritos a seguir.

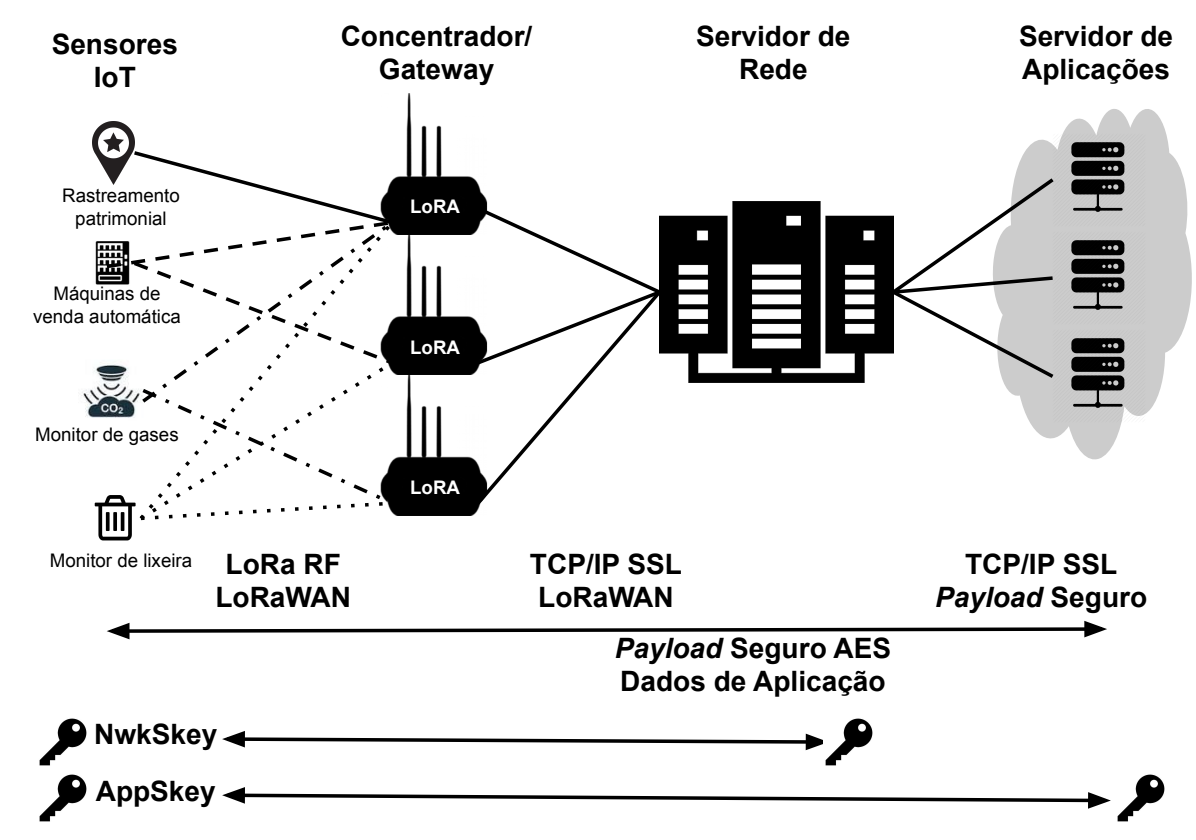

Figura 3.22. Topologia de uma rede LoRaWAN

- Dispositivos finais bidirecionais Classe A: as transmissões ascendentes (dispositivogateway) são baseadas no protocolo ALOHA. A recepção dos pacotes do gateway só pode ser realizada em duas curtas janelas de recepção que se abrem depois de uma transmissão. Essa classe fornece o menor consumo de energia, tendo como principal aplicação o monitoramento de grandezas.

- Dispositivos finais bidirecionais Classe B: além do modo classe A, são abertas janelas de transmissões (gateway-dispositivo) pré-programadas e gerenciadas por um sinal de temporização (Beacon), o qual indica quando o receptor está pronto para receber o sinal. Essa classe pode ser conveniente para sistemas de telecomando não sensíveis a tempo.

- Dispositivos finais bidirecionais Classe C: a janela de transmissão (gateway-dispositivo) está aberta continuamente, fechando-se apenas no momento da transmissão ascendente (dispositivo-gateway). 
Em relação à ativação dos dispositivos na rede, a rede LoRaWAN adota o algoritmo de criptografia AES-128, utilizando duas formas diferenciadas de ativação em razão do tipo de rede Pública ou Privada. Nas redes públicas, utiliza-se o OTAA (Over The Air Activation), o qual se baseia no envio de um identificador global único (DevEUI), análogo ao endereço MAC, do identificador (AppEUI) e chave da aplicação (AppKey) desejada. Esses dados são utilizados na camada de aplicação para validar e ativar o dispositivo em determinada aplicação na rede. Ocorrendo a aceitação na rede, o dispositivo recebe uma mensagem de join accept, a qual contém o endereço do dispositivo (DevAddr), a chave de sessão da rede (NwkSKey) e a chave de sessão da aplicação (AppSKey). Nas redes privadas, são necessários os seguintes dados para ativação: endereço do dispositivo (DevAddr), chave de sessão da rede (NwkSKey) e chave de sessão da aplicação (AppSKey), os quais são gravados no dispositivo, no momento da sua configuração. Desta forma, o dispositivo está pronto para comunicação, quando estiver conectado na rede.

$\mathrm{Na}$ arquitetura de uma rede LoRaWAN, ainda estão presentes os Servidores de Rede, que são responsáveis pelo gerenciamento das informações enviadas pelos gateways. Como existe a possibilidade de dois ou mais gateways receberem o mesmo pacote de um determinado dispositivo, o servidor de rede elimina pacotes duplicados, gerencia os tempos para retorno de reconhecimento (ACK - acknowledgement) e faz os ajustes para adaptar as taxas de dados (DR - Adaptative Data Rate) de forma a gerenciar os tempos entre as comunicações e o consumo de energia. Finalmente, a rede LoRaWAN possui um ou vários Servidores de Aplicações que recebem via requisição ou de forma automática os pacotes dos Servidores de Rede e, de acordo com a requisição, executam uma ou mais ações específicas fornecendo a interface necessária para as diversas aplicações clientes.

\subsubsection{Demonstração da integração de rede de acesso sem fio não-3GPP e o núcleo 5G}

\section{Objetivos}

O objetivo da demonstração é apresentar a integração de uma rede de acesso sem fio não-3GPP ao núcleo 5G. Além disso, esse experimento mostra a grande capilaridade que um sistema $5 \mathrm{G}$ pode ter, incluindo redes com frequências não licenciadas.

\section{Descrição}

Nesta demonstração, combinamos uma rede de acesso baseada em tecnologia LTE com uma rede sem fio LoRa implementada em hardware. Para rede de acesso LTE usamos uma implementação do projeto de código aberto com SDR. O núcleo da rede $5 \mathrm{G}$ é baseado na implementação da SBA também fornecida em código aberto e implementada em software. Todos os componentes são implementados utilizando contêineres Docker que podem ser hospedados em uma infraestrutura de nuvem. Conectado à rede de acesso através do LTE, há um gateway LoRA implementado em hardware genérico com suporte a múltiplos sensores IoT que sincronizam seus dados com o servidor LoRa presente na outra extremidade da infraestrutura. Sendo assim, para fins de demonstração, os dados coletados pelos sensores são transmitidos através da rede LoRa até o gateway que encaminha os dados através da rede LTE, passando pelo núcleo SBA da rede 5G até alcançar o servidor LoRa. A Figura 3.23 apresenta o experimento que implementamos para a de- 
monstração sobre a integração de uma rede de acesso sem fio não-3GPP com um núcleo de rede $5 \mathrm{G}$.

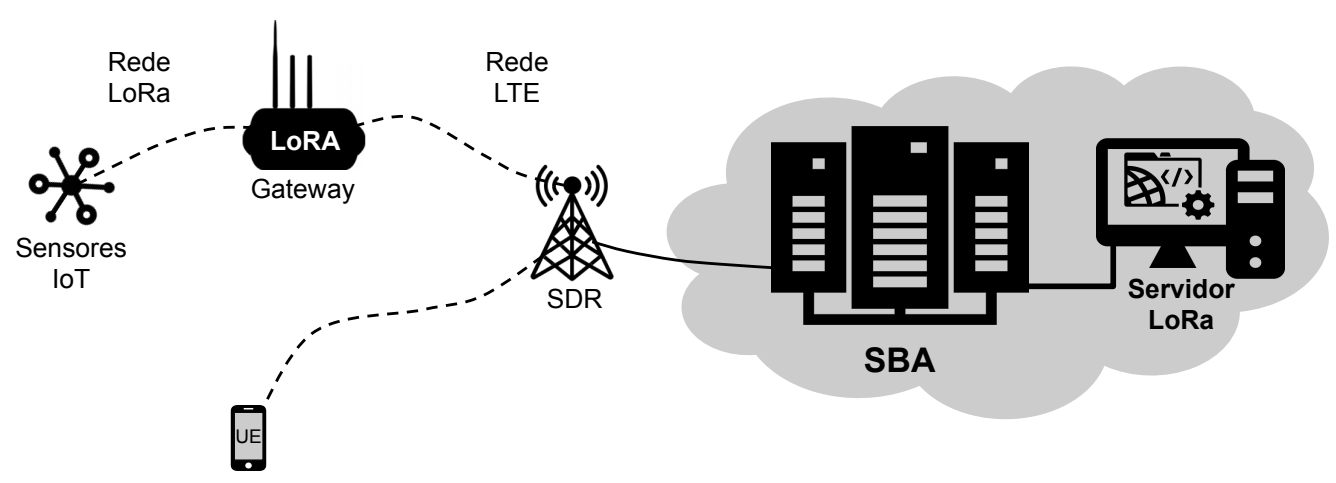

Figura 3.23. Demonstração da integração de redes heterogêneas.

\section{Mais informações}

Durante o minicurso é apresentado um vídeo de demonstração do experimento. Além disso, está disponível um manual com detalhes sobre como o experimento pode ser replicado. Por fim, contêineres e qualquer código extra produzido pela equipe e que sejam necessários para replicar o experimento estão também disponíveis publicamente.

Repositório deste minicurso:

https://github.com/LABORA-INF-UFG/SBRC2020-Minicurso3.

\subsection{Perspectivas futuras e Conclusão}

Como descrevemos previamente, a academia já começou a investigar potenciais desafios para a próxima geração de redes móveis sem fio. Naturalmente, ainda há muita incerteza e várias previsões podem não se consolidar. Por outro lado, alguns temas começam a ser abordados, ainda que de maneira incipiente, no roteiro de lançamentos da 3GPP. Por exemplo, nos Lançamentos 16 e 17 estão previstas melhorias em URLLC e o uso de SON para tornar mais eficiência de redes $5 \mathrm{G}$, sugerindo que previsões como MBRLLC e/ou mURLLC, assim como a ampla adoção de Aprendizado de Máquina (ML - Machine Learning) e Inteligência Artificial (AI - Artificial Intelligence), podem vir a se tornar realidade no futuro. A seguir, discutimos brevemente alguns tópicos abordados nos próximos dois lançamentos, previstos para junho de 2020 (Release 16) e setembro de 2021 (Release 17).

\section{Rede guiada por dados}

A introdução da NWDAF no Lançamento 15 é um passo importante para adoção de ML e AI em rede 5G, porém é apenas o começo. A especificação completa do arcabouço de coleta e análise de dados deve ser concluída no Lançamento 16. A partir desse ponto, soluções baseadas em ML e AI poderão utilizar as informações coletadas pela NWDAF para realizar tarefas como previsão e otimização da mobilidade, detecção de anomalias, previsão de QoS e correlação de dados. Nesse contexto, alguns dos objetivos 
para o Lançamento 17 são:

- Desempenho de rede previsível assistido pela NWDAF;

- Análise de dados orientada ao UE;

- Exposição da análise de dados da NWDAF para aplicações de usuário;

- NWDAF apoiando detecção de eventos anômalos e ajudando na análise de suas causas.

No longo prazo, o objetivo é usar técnicas de ML e AI para automatizar a gestão da rede com o mínimo de intervenção humana possível. É importante destacar que essa gestão deverá envolver diferentes tipos de redes (i.e., redes heterogêneas) se conectando a um núcleo comum, baseado na arquitetura SBA.

\section{Melhorias para domínios verticais}

Conforme comentado anteriormente, redes 5G foram projetadas com atenção especial para domínios verticais (comumente chamados apenas de verticais), isto é, setores ou grupos de empresas específicas em que produtos ou serviços semelhantes são desenvolvidos, produzidos e fornecidos. Nesse contexto, no Lançamento 16 existem várias direções e contribuições, por exemplo:

- Suporte a comunicações sensíveis a tempo (TSC - Time Sensitive Communication);

- Redes não públicas (NPNs - Non-Public Networks), i.e., redes privadas;

- Suporte para serviços do tipo rede local 5G (5G LAN);

- Serviços de localização avançados.

No Lançamento 17, estão previstas evoluções no suporte a NPNs e a serviços de proximidade (ProSe - Proximity Sservices), sendo esses também úteis em cenários de segurança pública.

\section{Evolução da segurança}

Segurança sempre foi uma preocupação em redes celulares, especialmente a partir de $3 \mathrm{G}$ com o uso mais amplo da infraestrutura para o transporte de dados e sua natural integração com a Internet. Portanto, a questão de segurança em redes $5 \mathrm{G}$ foi abordada desde seu projeto e tem sido um tema recorrente, sobretudo devido a importância estratégica que a $5 \mathrm{G}$ vem conquistando em termos econômicos e sociais. Existe uma lista de contribuições em segurança previstas para o Lançamento 16, da qual alguns itens relevantes são destacados a seguir:

- Suporte para NPNs com novos esquemas de autenticação;

- Opção de autenticação específica por fatia de rede (network slice), além da autenticação primária; 
- Segurança avançada para Controle de Recursos de Rádio (RRC - Radio Resource Control) e sinalização NAS;

- Suporte para proteção de integridade no plano de usuário, abrangendo os três cenários de redes 5G, i.e., eMBB, URLLC e mMTC.

\section{Outros avanços}

Há várias outras contribuições nos Lançamentos 16 e 17 que introduzem novas soluções, mas que também podem oferecer oportunidades para investigação em pesquisa. Isso ocorre porque determinadas soluções não estão completamente definidas, devido a fatores como complexidade do problema abordado ou impossibilidade de definir no padrão as especificidades que a solução terá que lidar. A seguir, listamos alguns temas desses dois Lançamentos (16 e 17) que, embora já tenham sido investigados, ainda apresentam questões em aberto, especialmente em um contexto prático e com potencial aplicação em larga escala.

- Avanços em V2X (Vehicle-to-everything) - formação de pelotão, direção autônoma e direção remota;

- Acesso a espectro não licenciado usando o 5G NR (New Radio);

- Compartilhamento Dinâmico do Espectro (DSS - Dynamic Spectrum Sharing);

- IoT em redes não terrestres (NTNs - Non Terrestrial Networks);

- Suporte a sistemas aéreos não tripulados (UAS - Unmanned Aerial Systems).

Finalmente, baseado no que foi apresentado nesse minicurso, podemos perceber a integração cada vez mais forte entre as áreas de Telecomunicação e Tecnologia da Informação. Por um lado, tem crescido a adoção de softwarização e modelo nativo em nuvem em sistemas 5G, i.e., RAN e núcleo. Por outro lado, tem crescido o interesse em criar soluções em software que atendam as necessidades específicas de redes móveis sem fio, como computação de borda e sistemas para processamento de sinais. Essa integração ainda será largamente explorada nos próximos anos, para tornar o desenvolvimento ainda mais ágil e interoperável. Exemplo dessa mudança de visão é a distribuição (a partir do Lançamento 15) das especificações da 3GPP no formato de serialização de dados legíveis (YAML YAML Ain't Markup Language) [65], permitindo a construção e desenvolvimento das interfaces padronizadas e com grande flexibilidade. Além disso, a utilização de tecnologias nativas de nuvem permitirá uma gerência e controle extremamente automatizados, com a mínima (ou até mesmo sem a) intervenção humana, que vem sendo chamado de ZSM (Zero touch network \& Service Management) [66]. Essas evoluções devem alterar o modelo de negócio das operadoras de telecomunicação, permitindo ampliar relações B2C (Business to Consumer) e B2B (Business to Business).

\section{Referências}

[1] Shafi, M. et al. 5G: A Tutorial Overview of Standards, Trials, Challenges, Deployment, and Practice. IEEE Journal on Selected Areas in Communications, v. 35, n. 6, p. 1201-1221, 2017. 
[2] Kaloxylos, A. A Survey and an Analysis of Network Slicing in 5G Networks. IEEE Communications Standards Magazine, v. 2, n. 1, p. 60-65, 2018.

[3] RICHTER, F. Global 5G Adoption to Take Off in 2021. 2019. https://www. statista.com/chart/9604/5g-subscription-forecast/. [Último acesso: 31mar-2020].

[4] World Economic Forum. The Impact of 5G: Creating New Value across Industries and Society. Jan 2020. https://www.weforum.org/whitepapers/ the-impact-of-5g-creating-new-value-across-industries-and-society. [Último acesso: 31-mar-2020].

[5] 3GPP. 4G; Release 8. 2009. https://wwW.3gpp.org/specifications/ releases/72-release-8. [Último acesso: 26-fev-2020].

[6] 3GPP. TR21.915: Technical Specification Group Services and System Aspects; Release 15 Description; Summary of Rel-15 Work Items (Release 15). [S.1.], 2018-12. Version 0.5.0.

[7] Abdelwahab, S. et al. Network function virtualization in 5G. IEEE Communications Magazine, v. 54, n. 4, p. 84-91, 2016.

[8] Chen, T. et al. Software defined mobile networks: concept, survey, and research directions. IEEE Communications Magazine, v. 53, n. 11, p. 126-133, 2015.

[9] FOUKAS, X. et al. Network slicing in 5G: Survey and challenges. IEEE Communications Magazine, v. 55, n. 5, p. 94-100, 2017.

[10] MADEMANN, F. The 5G System Architecture. Journal of ICT Standardization, v. 6, n. 3, p. 77-86, 2018.

[11] Palattella, M. R. et al. Internet of Things in the 5G Era: Enablers, Architecture, and Business Models. IEEE Journal on Selected Areas in Communications, v. 34, n. 3, p. 510-527, 2016.

[12] Lema, M. A. et al. Business Case and Technology Analysis for 5G Low Latency Applications. IEEE Access, v. 5, p. 5917-5935, 2017.

[13] Recommendation ITU-R M.2083-0. IMT Vision - Framework and overall objectives of the future development of IMT for 2020 and beyond. 2015. https://www. itu. int/dms_pubrec/itu-r/rec/m/R-REC-M.2083-0-201509-I ! !PDF-E.pdf.

[14] STALLINGS, W. Data and computer communications. 10. ed. [S.1.]: Prentice Hall, 2014.

[15] GAWAS, A. An overview on evolution of mobile wireless communication networks: 1G-6G. International Journal on Recent and Innovation Trends in Computing and Communication, v. 3, n. 5, p. 3130-3133, 2015. 
[16] NGUYEN, V.-G. et al. SDN/NFV-based mobile packet core network architectures: A survey. IEEE Communications Surveys $\mathcal{E}$ Tutorials, IEEE, v. 19, n. 3, p. 1567-1602, 2017.

[17] VAEZI, M.; DING, Z.; POOR, H. V. Multiple access techniques for $5 G$ wireless networks and beyond. [S.1.]: Springer, 2019.

[18] OJALA, P. et al. The adaptive multirate wideband speech codec: system characteristics, quality advances, and deployment strategies. IEEE Communications Magazine, IEEE, v. 44, n. 5, p. 59-65, 2006.

[19] GUILLOU, Y. L. et al. Highly integrated direct conversion receiver for GSM/GPRS/EDGE with on-chip 84-dB dynamic range continuous-time/spl Sigma//spl Delta/ADC. IEEE journal of solid-state circuits, IEEE, v. 40, n. 2, p. 403-411, 2005.

[20] BETTSTETTER, C.; VOGEL, H.-J.; EBERSPACHER, J. GSM phase 2+ general packet radio service GPRS: Architecture, protocols, and air interface. IEEE communications Surveys, IEEE, v. 2, n. 3, p. 2-14, 1999.

[21] CONDOLUCI, M.; MAHMOODI, T. Softwarization and virtualization in 5G mobile networks: Benefits, trends and challenges. Computer Networks, Elsevier, v. 146, p. $65-84,2018$.

[22] SUBRAMANYA, S.; YI, B. K. Mobile communications-an overview. IEEE Potentials, IEEE, v. 24, n. 5, p. 36-40, 2005.

[23] GHOSH, A. et al. 5G Evolution: A View on 5G Cellular Technology Beyond 3GPP Release 15. IEEE Access, IEEE, v. 7, p. 127639-127651, 2019.

[24] PUNZ, G. Evolution of $3 G$ networks: the concept, architecture and realization of mobile networks beyond UMTS. [S.1.]: Springer Science \& Business Media, 2009.

[25] 3GPP. TP-03075: Overview of 3GPP Release 99. 2003. ftp://www.3gpp. org/TSG_T/TSG_T/TSGT_22/Docs/PDF/TP-030275.pdf. [Último acesso: 22-apr2020].

[26] NOHRBORG, M. LTE Overview. aug 2012. [Último acesso: 11-mar-2020]. Disponível em: <https://www.3gpp.org/technologies/keywords-acronyms/98-lte>.

[27] PARKVALL, S.; FURUSKAR, A.; DAHLMAN, E. Evolution of LTE toward IMTadvanced. IEEE Communications Magazine, IEEE, v. 49, n. 2, p. 84-91, 2011.

[28] SACHS, J. et al. 5G radio network design for ultra-reliable low-latency communication. IEEE Network, IEEE, v. 32, n. 2, p. 24-31, 2018.

[29] WANNSTROM, J. LTE-advanced. Third Generation Partnership Project (3GPP), 2013. 
[30] SCHMITT, P.; LANDAIS, B.; YANG, F. Y. Control and User Plane Separation of EPC nodes (CUPS). aug 2012. [Último acesso: 25-mar-2020]. Disponível em: $<$ https://www.3gpp.org/news-events/1882-cups>.

[31] Rangan, S.; Rappaport, T. S.; Erkip, E. Millimeter-Wave Cellular Wireless Networks: Potentials and Challenges. Proceedings of the IEEE, v. 102, n. 3, p. 366385, 2014.

[32] Wang, X. et al. Millimeter Wave Communication: A Comprehensive Survey. IEEE Communications Surveys Tutorials, v. 20, n. 3, p. 1616-1653, 2018.

[33] Giordani, M. et al. A Tutorial on Beam Management for 3GPP NR at mmWave Frequencies. IEEE Communications Surveys Tutorials, v. 21, n. 1, p. 173-196, 2019.

[34] Zhang, D. et al. Fast Beam Tracking for Millimeter-Wave Systems Under High Mobility. In: ICC 2019 - 2019 IEEE International Conference on Communications (ICC). [S.1.: s.n.], 2019. p. 1-6.

[35] Samsung Electronics Co. 5G Core Vision - Samsung 5G Core Vol.1. [S.1.], 2019.

[36] SAAD, W.; BENNIS, M.; CHEN, M. A Vision of 6G Wireless Systems: Applications, Trends, Technologies, and Open Research Problems. CoRR, abs/1902.10265, 2019. Disponível em: <http://arxiv.org/abs/1902.10265>.

[37] Giordani, M. et al. Toward 6G Networks: Use Cases and Technologies. IEEE Communications Magazine, v. 58, n. 3, p. 55-61, 2020.

[38] CHEN, Z. et al. A survey on terahertz communications. China Communications, IEEE, v. 16, n. 2, p. 1-35, 2019.

[39] Semiari, O. et al. Integrated Millimeter Wave and Sub-6 GHz Wireless Networks: A Roadmap for Joint Mobile Broadband and Ultra-Reliable Low-Latency Communications. IEEE Wireless Communications, v. 26, n. 2, p. 109-115, 2019.

[40] Peng, M. et al. Self-configuration and self-optimization in LTE-advanced heterogeneous networks. IEEE Communications Magazine, v. 51, n. 5, p. 36-45, 2013.

[41] Letaief, K. B. et al. The Roadmap to 6G: AI Empowered Wireless Networks. IEEE Communications Magazine, v. 57, n. 8, p. 84-90, 2019.

[42] Adadi, A.; Berrada, M. Peeking Inside the Black-Box: A Survey on Explainable Artificial Intelligence (XAI). IEEE Access, v. 6, p. 52138-52160, 2018.

[43] Taleb Zadeh Kasgari, A.; Saad, W.; Debbah, M. Human-in-the-Loop Wireless Communications: Machine Learning and Brain-Aware Resource Management. IEEE Transactions on Communications, v. 67, n. 11, p. 7727-7743, 2019.

[44] Marotta, M. A. et al. Characterizing the Relation Between Processing Power and Distance Between BBU and RRH in a Cloud RAN. IEEE Wireless Communications Letters, v. 7, n. 3, p. 472-475, 2018. 
[45] 3GPP. TR38.801: 33rd Generation Partnership Project; Technical Specification Group Radio Access Network; Study on new radio access technology: Radio access architecture and interfaces (Release 14). [S.1.], 2017-03. Version 14.0.0.

[46] Gonzalez-Diaz, S. et al. Integrating fronthaul and backhaul networks: Transport challenges and feasibility results. IEEE Transactions on Mobile Computing, p. 1-18, 2019.

[47] FONSECA, F.; CORREA, S.; CARDOSO, K. Optimizing allocation and positioning in a disaggregated radio access network aware of paths through the core infrastructure. In: Anais do XXXVII Simpósio Brasileiro de Redes de Computadores e Sistemas Distribuídos. [S.1.: s.n.], 2019. p. 791-804.

[48] Karnouskos, S. et al. A SOA-based architecture for empowering future collaborative cloud-based industrial automation. In: IECON 2012 - 38th Annual Conference on IEEE Industrial Electronics Society. [S.1.: s.n.], 2012. p. 5766-5772. ISSN 1553-572X.

[49] Imadali, S.; Bousselmi, A. Cloud Native 5G Virtual Network Functions: Design Principles and Use Cases. In: 2018 IEEE 8th International Symposium on Cloud and Service Computing (SC2). [S.1.: s.n.], 2018. p. 91-96.

[50] HEDMAN, P. et al. 5G Core Networks: Powering Digitalisation. [S.1.]: Elsevier Science \& Technology, 2019. ISBN 9780081030097.

[51] 3GPP. TS133.185: 3rd Generation Partnership Project Technical Specification Group Services and Systems Aspects Release 14 Description. [S.1.], 2017-10. Version 14.1.0.

[52] TOSKALA, A.; POIKSELKÄ, M. 5G Architecture. 5G Technology: 3GPP New Radio, Wiley Online Library, p. 67-86, 2020.

[53] ETSI. TS 123 501: System architecture for the 5G System (5GS)(3GPP TS 23.501 version 15.5.0 Release 15. [S.1.], 2019. Version 15.5.0.

[54] Choyi, V. K. et al. Network slice selection, assignment and routing within 5G Networks. In: IEEE Conference on Standards for Communications and Networking (CSCN). [S.1.: s.n.], 2016. p. 1-7.

[55] PARKVALL, S. et al. NR: The new 5G radio access technology. IEEE Communications Standards Magazine, IEEE, v. 1, n. 4, p. 24-30, 2017.

[56] 3GPP. 5G; Access to the 3GPP 5G Core Network (5GCN) via non-3GPP access networks (Release 15). 2019. https://www.etsi.org/deliver/etsi_ ts/124500_124599/124502/15.02.00_60/ts_124502v150200p.pdf. [Último acesso: 03-fev-2020].

[57] WBA and NGMN Alliance. RAN Convergence Paper. 2019. https://wballiance.com/wp-content/uploads/2019/01/ RAN-Convergence-Paper-2019.pdf. [Último acesso: 03-fev-2020]. 
[58] Navarro-Ortiz, J. et al. Integration of LoRaWAN and 4G/5G for the Industrial Internet of Things. IEEE Communications Magazine, v. 56, n. 2, p. 60-67, Feb 2018.

[59] Yasmin, R. et al. On the integration of LoRaWAN with the 5G test network. In: 2017 IEEE 28th Annual International Symposium on Personal, Indoor, and Mobile Radio Communications (PIMRC). [S.1.: s.n.], 2017. p. 1-6.

[60] OLSSON, M. et al. EPC and $4 G$ packet networks: driving the mobile broadband revolution. [S.1.]: Academic Press, 2013.

[61] SEMTECH. Semtech Corporation. 2020. https://www. semtech.com/. [Último acesso: 22-abril-2020].

[62] Shanmuga Sundaram, J. P.; Du, W.; Zhao, Z. A survey on lora networking: Research problems, current solutions, and open issues. IEEE Communications Surveys Tutorials, v. 22, n. 1, p. 371-388, 2020.

[63] JungWoon Lee et al. Risk analysis and countermeasure for bit-flipping attack in lorawan. In: International Conference on Information Networking (ICOIN). [S.1.: s.n.], 2017. p. 549-551.

[64] HAXHIBEQIRI, J. et al. A Survey of LoRaWAN for IoT: From Technology to Application. Sensors, v. 18, p. 3995, 112018.

[65] 3GPP. OpenAPI. feb 2020. [Último acesso: 26-abril-2020]. Disponível em: $<$ https://www.3gpp.org/FTP/Specs/archive/OpenAPI/>.

[66] ETSI. Zero-touch network and Service Management (ZSM); Terminology for concepts in ZSM. [S.1.], 2019. V1.1.1. Disponível em: $<$ https://www.etsi.org/technologies/zero-touch-network-service-management>. 